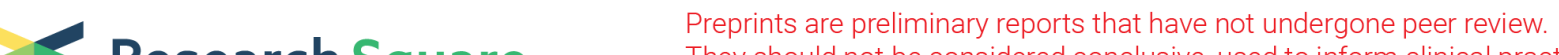 $\begin{array}{ll}\text { Research Square } & \begin{array}{l}\text { They should not be considered conclusive, used to inform clinical practice, } \\ \text { or referenced by the media as validated information. }\end{array}\end{array}$
}

\section{A Functional Interaction Between the SARS-CoV-2 Spike Protein and the Human a7 Nicotinic Receptor}

\section{Juan Facundo Chrestia}

INIBIBB- UNS/CONICET

\section{Ana Sofia Oliveira}

University of Bristol School of Chemistry

Adrian J Mulholland

University of Bristol School of Chemistry

Timothy Gallagher

University of Bristol School of Chemistry

Isabel Bermúdez

Oxford Brookes University

Cecilia Bouzat ( $\square$ inbouzat@criba.edu.ar)

INIBIBB- UNS/CONICET https://orcid.org/0000-0003-0388-6129

\section{Research Article}

Keywords: nicotinic receptor, neurotransmitter receptors, single-channel recordings, patch-clamp, SARSCoV-2 spike protein

Posted Date: January 21st, 2022

DOl: https://doi.org/10.21203/rs.3.rs-938911/v2

License: (c) (i) This work is licensed under a Creative Commons Attribution 4.0 International License.

Read Full License 


\title{
A Functional Interaction Between the SARS-CoV-2 Spike Protein and the Human a7 Nicotinic Receptor
}

\author{
Juan Facundo Chrestia ${ }^{1}$, Ana Sofia Oliveira ${ }^{2}$, Adrian J. Mulholland ${ }^{2}$, Timothy Gallagher ${ }^{3}$, Isabel \\ Bermúdez ${ }^{4 *}$ and Cecilia Bouzat ${ }^{1 *}$ \\ ${ }^{1}$ Instituto de Investigaciones Bioquímicas de Bahía Blanca, Departamento de Biología, \\ Bioquímica y Farmacia, Universidad Nacional del Sur-Consejo Nacional de Investigaciones \\ Científicas y Técnicas (CONICET), Bahía Blanca, Argentina. \\ ${ }^{2}$ Centre for Computational Chemistry, School of Chemistry, University of Bristol, Bristol BS8 1TS. \\ ${ }^{3}$ School of Chemistry, University of Bristol, Bristol, United Kingdom. \\ ${ }^{4}$ Department of Biological and Medical Sciences, Oxford Brookes University, Oxford OX3 0BP, \\ United Kingdom.
}

\section{Corresponding authors:}

Cecilia Bouzat (inbouzat@criba.edu.ar). Instituto de Investigaciones Bioquímicas de Bahía Blanca -Camino La Carrindanga Km 7- 8000 Bahía Blanca-Argentina.

Isabel Bermúdez (ibermudez@brookes.ac.uk). Department of Biological and Medical Sciences, Oxford Brookes University, Oxford OX3 0BP, UK.

\section{ORCID}

Juan Facundo Chrestia. 0000-0002-5223-383X

Ana Sofía Oliveira. 0000-0001-8753-4950

Adrian J. Mulholland. 0000-0003-1015-4567

Timothy Gallagher. 0000-0002-3544-327X

Isabel Bermúdez. 0000-0001-7692-1509

Cecilia Bouzat. 0000-0003-0388-6129

Funding: This work was supported by grants from Universidad Nacional del Sur (PGI 24/B298) and Agencia Nacional de Promoción Científica y Tecnológica (PICT 2017-1170) to CB; Oxford Brookes University (REA-2020) to IB. AJM and ASFO thank EPSRC (grant number EP/M022609/1) and BBSRC (grant number BB/R016445/1) for support. We thank BrisSynBio, a BBSRC/EPSRC Synthetic Biology Research Centre (Grant Number:BB/L01386X/1), for funding ASFO and providing funds to purchase the Y674-R685 peptide from Designer Bioscience Ltd. (Cambridge UK).

The authors report no conflict of interest.

Acknowledgements: We thank Dr. Franco Vizcarra (Oxford Brookes University) for helping with the whole-cell recordings.

Author Contributions: JFC, ASFO, AJM, TG, IB and CB designed the research; JFC, ASFO, IB and $\mathrm{CB}$ performed the research and analysed the data; CB, ASFO, AJM, TG, JFC and IB wrote, reviewed, and edited the paper. 


\begin{abstract}
Coronavirus disease 2019 (COVID-19) is caused by the severe acute respiratory syndrome coronavirus 2 (SARS-CoV-2). Infection relies on the binding of the viral spike protein (S) to angiotensin-converting enzyme 2 in host cells. Regions of the $S$ protein have been suggested to interact with nicotinic acetylcholine receptors ( $\mathrm{nAChRs}$ ), and a potential contribution of nAChRs to COVID-19 pathophysiology has been proposed. $\alpha 7 \mathrm{nAChR}$ is an interesting candidate target since it is present in neuronal and non-neuronal cells, including immune cells, and has antiinflammatory actions. We here identified a novel direct functional interaction between the $\alpha 7$ $\mathrm{nAChR}$ and a region of the S protein (Y674-R685). The $\mathrm{S}$ fragment exerts a dual effect, acting as a low-efficacy agonist and a non-competitive inhibitor. It activates the $\alpha 7 \mathrm{nAChR}$, in line with our previous molecular dynamics simulations showing favorable binding of this accessible region of the $S$ protein to the nAChR agonist binding pocket. However, activation requires the presence of positive allosteric modulators that enhance channel opening probability, indicating very low activation efficacy. The $S$ fragment exerts an additional inhibition, which may be the predominant effect on $\alpha 7$ responses. This study reveals a functional interaction between $\alpha 7$ and the Y674R685 fragment of the S protein, which opens doors for exploring the involvement of nAChRs in COVID-19 pathophysiology.
\end{abstract}

Running title: $\alpha 7-$ SARS-CoV-2 spike protein interaction

Key words: nicotinic receptor, neurotransmitter receptors, single-channel recordings, patchclamp, SARS-CoV-2 spike protein.

\title{
Abbreviations
}

SARS-CoV-2: severe acute respiratory syndrome coronavirus 2 nAChR: Nicotinic Acetylcholine Receptor.

ACh: Acetylcholine.

MLA: methyllycaconitine

PAM: Positive Allosteric Modulator.

5-HI: 5-Hydroxyindole.

PNU-120596: (N-(5-Chloro-2,4-dimethoxyphenyl)- N'-(5-methyl-3-isoxazolyl)-urea)

S protein: SARS-CoV-2 Spike protein

MD: Molecular dynamics

CRC: concentration-response curve 


\section{INTRODUCTION}

The emergence of the severe acute respiratory syndrome coronavirus-2 (SARS-CoV-2) in late 2019 changed and reshaped the world in lasting ways. Even though several COVID-19 vaccines are now available, the ongoing pandemic caused by this virus remains a global crisis with extensive negative economic, social, and health impacts. Important efforts have been made to understand the nature of this virus, its mutations, host interactions and transmission routes. This information is required to drive vaccine and therapeutic discovery and to develop effective strategies to stop the current (and future) outbreaks.

The mechanism of SARS-CoV-2 infection starts with the virus-host cell recognition, which is mediated by the viral spike (S) protein (Fig. 1A). The S protein is a homotrimeric type I fusion glycoprotein found on the surface of the virion and is composed of two subunits, S1 and S2 (Supplementary Fig. 1) [1]. S1 binds with high affinity to the human angiotensin-converting enzyme 2 (ACE2) and induces membrane fusion allowing for the delivery of the viral RNA into the host cell [2,3]. Infectivity is enhanced by additional interactions between $\mathrm{S} 1$ and the neuropilin 1 receptor $[4,5]$. The $S$ protein has been suggested to contribute to COVID-19 pathophysiology also through direct or indirect interactions with other proteins, such as nicotinic acetylcholine receptors (nAChRs) [6-8], and epithelial sodium channels [9].

A

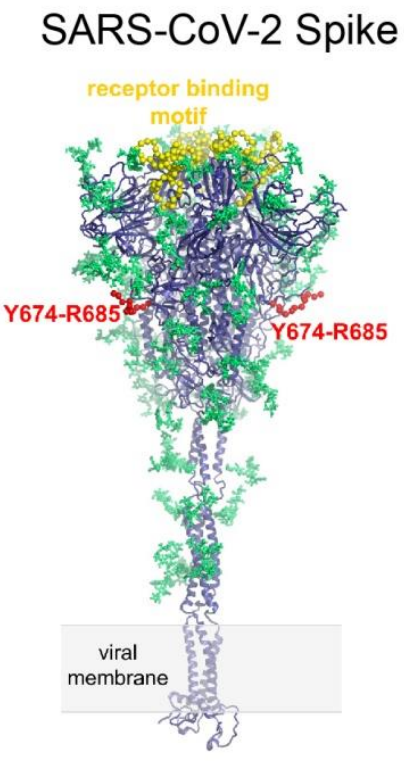

C

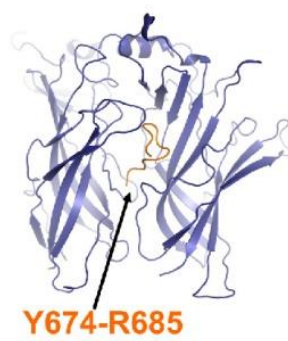

B

$\alpha 7 \mathrm{nAChR}$
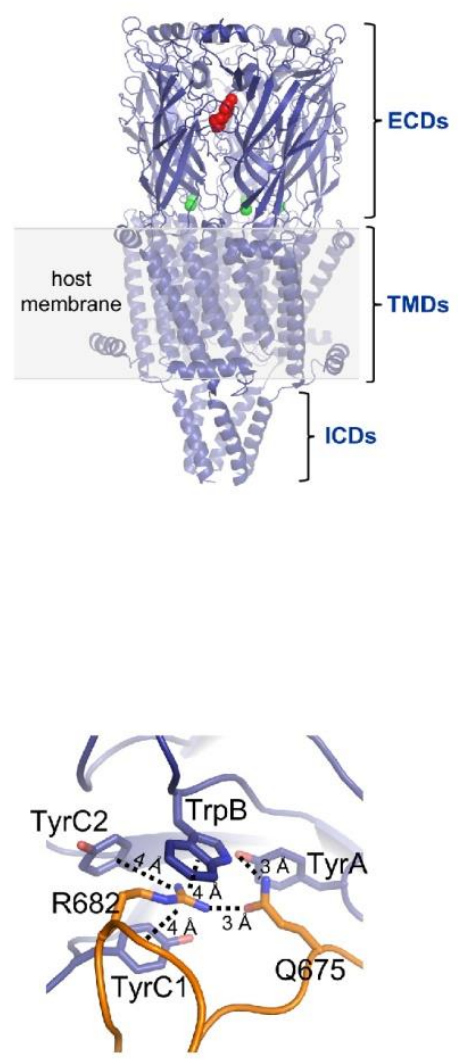

Figure 1. Three-dimensional structures of the SARS-CoV-2 S protein and the human $\alpha 7$ nAChR. 
A. The model represents the complete, fully glycosylated $S$ protein in the closed state after furin cleavage [1]. The protein is rendered as a blue cartoon with the glycans depicted in green. The receptor binding motifs (residues S438-Q506) and the Y674-R685 region are highlighted in yellow and red, respectively. The Y674-R685 region was shown to be accessible for binding in previous $M D$ simulations of the fully glycosylated $S$ protein [8].

B. Cryo-EM structure of the human $\alpha 7 n A C h R$ (PDB code: $7 K O X)$ [43]. This receptor is a homopentamer formed of five $\alpha 7$ subunits. Each subunit is composed of an extracellular (ECD), transmembrane (TMD) and intracellular (ICD) domain. The agonist binding site is located in the $E C D$ at the interface between two neighbouring subunits. In this structure, epibatidine (red spheres) is bound to the agonist binding site. The green spheres represent bound calcium ions. C. MD simulations of Y674-R685 bound to the human $\alpha 7 n A C h R$ show favourable binding to the binding pocket [8]. Example of conformations from simulations in which the most important interactions with conserved key aromatic residues are present. Left: Overall view of the Y674R685: $\alpha 7(E C D)$ complex. Right: Close-up view of interactions formed by R682 and Q675 within agonist binding site. The $\alpha 7$ receptor and Y674-R685 are coloured in dark blue and orange, respectively. Interactions between side chains of R682 and Q675 and the aromatic rings of TrpB

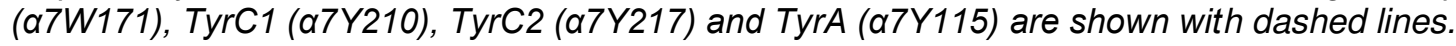

The potential interaction of SARS-CoV-2 with nAChRs was first postulated by Changeux and colleagues [6]. It was described that the sequence of the C-terminus region of the S1 subunit (region Y674-R685), which is an exposed loop, contains a motif that is homologous to a motif of snake neurotoxins, which are antagonists of nAChRs, and to a short region of the ectodomain of the rabies virus glycoprotein (RABv) [6], which has been shown to inhibit ACh-elicited macroscopic currents of $\alpha 4 \beta 2$ nAChRs [10].

We recently examined the possible binding of the Y674-R685 region of the S protein to several nAChRs using molecular dynamics (MD) simulations [8]. These simulations predicted favourable binding of the $Y 674-R 685$ region to the agonist binding site of the human $\alpha 4 \beta 2$ and $\alpha 7$ (Fig. 1B and C) nAChRs and the muscle-like $\alpha \beta \gamma \delta$ receptor from Tetronarce californica [8]. Moreover, analyses of the MD simulations of the complete and fully glycosylated $S$ protein showed that the Y674-R685 region is accessible for binding [8]. Among nAChRs, binding of Y674-R685 to the $\alpha 7$ subtype is highly relevant to COVID-19 as nicotine, acting through this receptor, may regulate the expression of ACE2 [11]. Also, activation of $\alpha 7 \mathrm{nAChR}$ reduces inflammation and tissue damage by downregulating pro-inflammatory cytokines [12-14]. Thus, potentiation of $\alpha 7$ has emerged as an important strategy for modulating inflammation in different pathological contexts, including acute respiratory distress syndrome [14,15]. Hence, ligands that bind $\alpha 7 \mathrm{nAChR}$ may affect the SARS-CoV-2 infectivity and the progression of COVID-19. Indeed, recently it has been shown that varenicline, a full agonist at $\alpha 7 \mathrm{nAChR}$ [16], reduces infectivity and disease progression in a rhesus macaque model [17].

Here, we use whole-cell and single-channel patch clamp recordings to determine whether the Y674-R685 region of the SARS-CoV-2 S protein can directly affect the human a7 nAChR. Our results reveal that this region acts as a very low-efficacy agonist of $\alpha 7$ since it activates the receptor but only in the presence of a potentiator. Additionally, the Y674-R685 fragment allosterically inhibits $\alpha 7$ responses at a wide concentration range. This functional interaction may play a role in infectivity and/or disease progression and provides foundations for new therapeutic opportunities. 


\section{MATERIALS AND METHODS}

\section{Chemicals.}

Acetylcholine (ACh) and 5-Hydroxyindole (5-HI) were purchased from Merck (USA). PNU-120596 (N-(5-Chloro-2,4-dimethoxyphenyl)-N'-(5-methyl-3-isoxazolyl)-urea) was obtained from Tocris Biosciences (Bristol, UK). Stock solutions were prepared in water (ACh, 5-HI) or DMSO (PNU120596). The fragment of the S protein (S) of SARS-COV-2, called Y674-R685, contains 12 amino acids with the sequence YQTQTNSPRRAR (MW 1477.60). The peptide was synthesized ( $90 \%$ purity) by Designer Bioscience Ltd. (Cambridge UK) and stored as $1 \mathrm{mM}$ stock solutions (in water) at $-20{ }^{\circ} \mathrm{C}$.

\section{Expression of human $\alpha 7$ in mammalian cells.}

BOSC-23 cells, derived from HEK-293 cells (kindly provided by Dr. Sine, Mayo Clinic, USA), were cultured with Dulbecco's Modified Eagle Medium (DMEM) culture medium (GIBCO, USA) supplemented with $100 \mu \mathrm{g} / \mathrm{mL}$ streptomycin $-100 \mathrm{IU} / \mathrm{mL}$ penicillin (Invitrogen, USA), $10 \%$ Fetal Bovine Serum (FBS, Internegocios, Argentina). Human a7 cDNA subunit (GenBank accession no X70297.1) was subcloned into the pRBG4 expression vector [18,19]. BOSC-23 cells were transfected by the calcium phosphate procedure with $\alpha 7$ subunit cDNA together with the $\alpha 7$ chaperones Ric-3 and NACHO cDNAs [20,21]. The cDNA ratio was 1:2:1 for $\alpha 7:$ Ric-3:NACHO, and the total amount was $4.2 \mu \mathrm{g} / 35 \mathrm{~mm}$ dish. Also, green fluorescence protein (GFP) cDNA plasmid was included to allow the identification of transfected cells [22,23].

All transfections were carried out for about 8-12 h in DMEM with $10 \%$ FBS and terminated by exchanging the medium. Cells were used for experiments two to three days after transfection, at which time maximum functional expression levels were achieved $[18,24,25]$.

\section{Single-channel recordings in BOSC-23 cells.}

Single channels were recorded in the cell-attached patch configuration at -70 $\mathrm{mV}$ [25]. Each patch corresponds to a different cell ( $\mathrm{n}$ indicates the number of independent experiments). For each condition, at least three different cell transfections from distinct days were performed $(\mathrm{N}$ indicates the number of cell transfections).

The bath and pipette solutions contained $142 \mathrm{mM} \mathrm{KCl}, 5.4 \mathrm{mM} \mathrm{NaCl}, 1.8 \mathrm{mM} \mathrm{CaCl}, 1.7$ $\mathrm{mM} \mathrm{MgCl} 2$ and $10 \mathrm{mM} \mathrm{HEPES} \mathrm{(pH} \mathrm{7.4).} \mathrm{The} \mathrm{peptide} \mathrm{and} \mathrm{5-HI} \mathrm{dissolved} \mathrm{in} \mathrm{water} \mathrm{were} \mathrm{added}$ directly to the pipette solution. PNU-120596 in DMSO was added either to the pipette solution or to the dish. The final concentration of DMSO was lower than $0.1 \%(\mathrm{v} / \mathrm{v})$, which does not affect $\alpha 7$ activation properties [19].

Single-channel currents were digitized at 5-10 $\mu$ s intervals and low-pass filtered at a cut-off frequency of $10 \mathrm{kHz}$ using an Axopatch 200B patch-clamp amplifier (Molecular Devices, CA, USA). Analysis was performed with the program TAC (Bruxton Corporation, Seattle, WA, USA) with the Gaussian digital filter at $9 \mathrm{kHz}$ (Final cut-off frequency $6.7 \mathrm{kHz}$ ) or at $3 \mathrm{kHz}$ for recordings in the presence of PNU-120596. Events were detected by the half-amplitude threshold criterion [25].

Open-time histograms were fitted by the sum of exponential functions by maximum likelihood using the program TACFit (Bruxton Corporation, Seattle, WA, USA). The duration of the slowest open component was used for comparisons. Bursts of channel openings were identified as a series of closely separated openings preceded and followed by closings longer than a critical duration, which was taken as the point of intersection between closed components as previously described [24-26]. For $\alpha 7$ activated by ACh, the critical duration for defining a burst was defined by the intersection between the first and second briefest components in the closed-time histogram ( 200-400 $\mu \mathrm{s})$. For defining bursts in the presence of 5-HI, critical times were selected 
between the second and third closed components ( 1-3 ms) $[24,26]$. In the presence of PNU120596 and ACh, $\alpha 7$ openings are grouped in bursts, and several bursts form long clusters. Each cluster corresponds to the activation episode of the same receptor molecule. For bursts, the critical time was set at 200-400 $\mu \mathrm{s}$, and for clusters, the critical time was determined by the point of intersection between the third and fourth closed components ( $30-60 \mathrm{~ms})$ [24]. The burst and cluster durations were taken from the slowest components of the corresponding histograms $[24,25]$.

\section{Expression of $\alpha 7 \mathrm{nAChR}$ in Xenopus laevis oocytes.}

Adult female Xenopus laevis were purchased from Xenopus One, MI, USA. Xenopus care and housing followed the UK Home Office code of practice guidelines for the species. Stage V and VI Xenopus oocytes were prepared as previously described [27], and then injected with 2-6 ng of human $\alpha 7$ subunit cDNA into the nucleus in a volume of $23.0 \mathrm{~nL}$, using a Nanoject Automatic Oocyte Injector (Drummond, Broomall, USA). To favour the expression of $\alpha 7$, its cDNA was coinjected with chaperone NACHO cDNA (GenBank accession no BC050273.1) $[21,28]$ at a ratio of 1 a7: $0.01 \mathrm{NACHO}$. Injected oocytes were incubated until use at $18^{\circ} \mathrm{C}$ in a solution (OR2) containing $82 \mathrm{mM} \mathrm{NaCl}, 2 \mathrm{mM} \mathrm{KCl}, 2 \mathrm{mM} \mathrm{MgCl}$, $5 \mathrm{mM}$ HEPES; $\mathrm{pH}$ 7.5, supplemented with 0.1 $\mathrm{mg} / \mathrm{mL}$ streptomycin, $1000 \mathrm{U} / \mathrm{mL}$ Penicillin and $100 \mu \mathrm{g} / \mathrm{mL}$ amikacin. Oocytes were used for electrophysiological recordings one to two days after injection $[27,28]$.

\section{Electrophysiological recordings in Xenopus laevis oocytes.}

Oocytes were impaled with two electrodes filled with $3 \mathrm{M} \mathrm{KCl}$, and the voltage-clamp was maintained at $-60 \mathrm{mV}$ throughout the experiment. All recordings were performed at $18^{\circ} \mathrm{C}$, and cells were perfused continuously with OR2 solution at $\mathrm{pH}$ 7.4. Currents were recorded using an automated platform equipped with standard two electrode voltage-clamp configuration (HiClamp; Multi Channel Systems, Reutlignen, Germany). This system differs from standard electrophysiology and other automated platforms because, instead of applying the compound in the perfusion, the oocyte is moved into a well from a 96-well microtiter plate containing $230 \mu \mathrm{l}$ of the desired solution, as previously described [27]. Experiments were carried out only if the resting potential of the impaled oocytes was greater than $-10 \mathrm{mV}$ and the total holding current less than $0.2 \mu \mathrm{A}$.

The ability of fragment Y674-R685 to evoke current responses in Xenopus oocytes expressing $\alpha 7 \mathrm{nAChR}$ was examined at a range of concentrations $(1 \mathrm{pM}-10 \mu \mathrm{M})$ along with control EC $50(100 \mu \mathrm{M})$ ACh-evoked responses from the same cells. Compounds were applied for $20 \mathrm{~s}$ and the washout period was 5 min. For experiments that assessed the effects PNU-120596 on the ability of fragment Y674-R685 to activate $\alpha 7 \mathrm{nAChRs}$, oocytes displaying maximal ACh current amplitudes of 15-20 $\mu \mathrm{A}$ were used. Our limit of detection for $\alpha 7$ receptor-mediated activity is $0.05-0.08 \%(10-20 \mathrm{nA}$ of current) of the maximal responses elicited by $1 \mathrm{mM} \mathrm{ACh}$.

To obtain concentration response data for the inhibitory effects of Y674-R685 on $\alpha 7$ $\mathrm{nAChRs}$, a range of concentrations of the fragment $(0.1 \mathrm{nM}$ to $30 \mu \mathrm{M})$ were co-applied with $\mathrm{ACh}$ $\mathrm{EC}_{50}(100 \mu \mathrm{M})$. The peaks of the current responses obtained in this manner were then normalised to the peak of the responses elicited by ACh alone. The effects of the fragment on the ACh concentration response curve (CRC) were assessed by determining the ACh CRC in the absence and presence of $1 \mu \mathrm{M}$ Y674-R685. The peak of the ACh responses were normalised to the responses elicited by $1 \mathrm{mM} \mathrm{ACh}$. For both set of studies, the normalised data were fit with the Hill equation using GraphPad software version 5, as previously described [27]. Data are expressed as means \pm SEM from 5-6 oocytes obtained from at least three different batches of oocytes $(N)$. Data were filtered at $10 \mathrm{~Hz}$, captured at $100 \mathrm{~Hz}$ using proprietary data acquisition software running under Matlab (Mathworks Inc., Natick, MA). 


\section{Statistical analysis.}

Single-channel data are presented as mean \pm SD. Data sets that passed the Shapiro-Wilk test for normality and the Levene Median test for equal variance were analyzed using two-tailed Student's t-test for pairwise comparisons or Mann-Whitney rank sum test with SigmaPlot 12.0 (Sysat Software, Inc.). Statistically significant differences between two groups of data were established at $p$ values $<0.05$. For each condition, $n$ indicates the number of independent experiments, each from different cell patches, and $\mathrm{N}$, the number of cell transfections, each from different days and cell batches. 


\section{RESULTS}

\section{a7 nAChR activation by the Y674-R685 fragment from the SARS-CoV-2 S protein in the presence of potentiators.}

Our previous MD simulations of the complex formed between the $\alpha 7$ nAChR and the Y674-R685 fragment from the SARS-CoV-2 S protein suggested the potential of the Y674-R685 region to interact with conserved aromatic residues within the binding pocket of the receptor (Fig. 1C) [8]. To establish unequivocally the existence of molecular functional interactions between this region of SARS-CoV-2 S protein and the human $\alpha 7 \mathrm{nAChR}$, we evaluated whether the synthetic fragment could elicit macroscopic and high-resolution single-channel currents.

The macroscopic responses of the human $\alpha 7 \mathrm{nAChR}$ expressed in Xenopus oocytes to the applications of the Y674-R685 fragment at a range of concentrations ( $1 \mathrm{pM}-10 \mu \mathrm{M})$ were examined along with control ACh-evoked responses from the same cells (Fig 2A). As shown in the figure, Y674-R685 did not elicit detectable currents in contrast to the robust responses elicited by $100 \mu \mathrm{M}$ ACh. After 5 min wash, receptors remained responsive to subsequent control applications of ACh (Fig. 2A).

Single-channel currents from cell-attached patches from BOSC-23 cells expressing human $\alpha 7 \mathrm{nAChR}$ were also recorded, thus allowing for more detailed mechanistic information. Recordings were carried out in parallel with control experiments with ACh as the agonist to confirm the presence of functional $\alpha 7 \mathrm{nAChRs}$ in the same batch of cells. ACh (10-100 $\mu \mathrm{M})$ evoked isolated brief openings or less often short bursts composed of a few openings in quick succession, which correspond to activation of the same receptor molecule $[19,22,23,25,26]$ (Fig. 2B). In contrast, channel activity was not detected at a range of Y674-R685 concentrations in a total of 21 patches from different cell transfections ( $1 \mathrm{pM}, \mathrm{n}=3 ; 1 \mathrm{nM}, \mathrm{n}=3 ; 1 \mu \mathrm{M}, \mathrm{n}=8 ; 10 \mu \mathrm{M}, \mathrm{n}=3$; $100 \mu \mathrm{M}, \mathrm{n}=4$ ) (Fig. 2B).

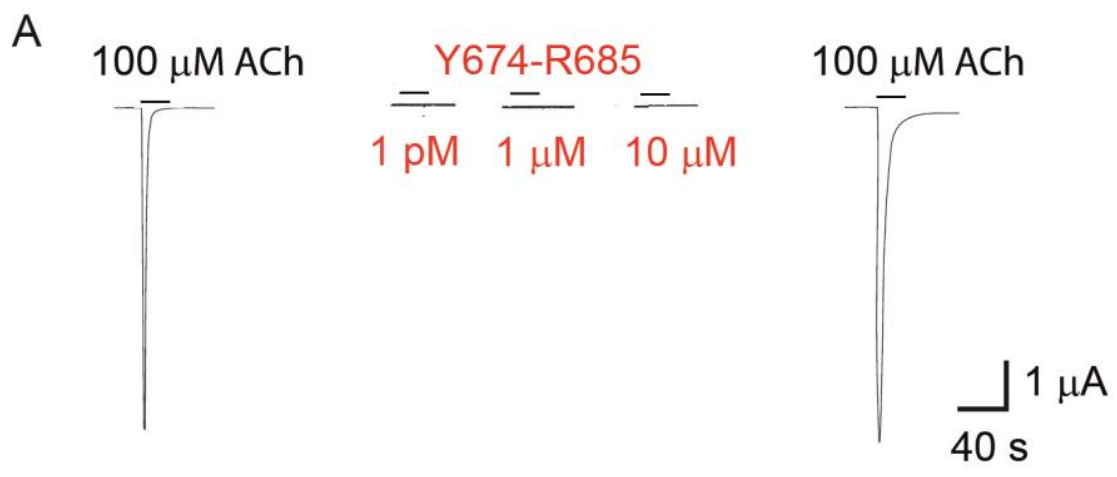

B

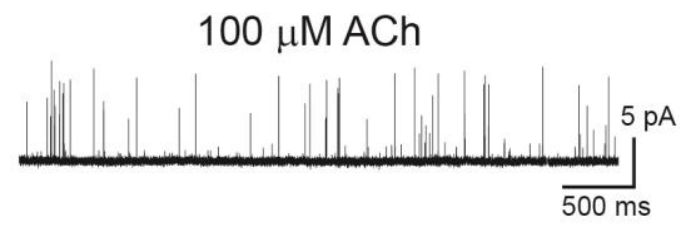

$10 \mu \mathrm{M}$ Y674-R685

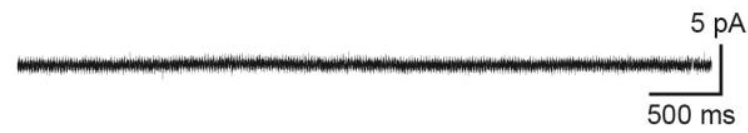

Figure 2. The Y674-R685 fragment cannot elicit detectable $\alpha 7$ responses. 
A. Macroscopic responses of the human $\alpha 7 n A C h R$. Representative traces from single oocytes expressing human $\alpha 7 \mathrm{nAChR}$ to applications of $\mathrm{ACh}(100 \mu \mathrm{M})$ or $1 \mathrm{pM}, 1 \mu \mathrm{M}$ or $10 \mu \mathrm{M}$ of Y674R685. Drug applications were for $20 \mathrm{~s}$ followed by a $300 \mathrm{~s}$ washout.

B. Single-channel currents of the human $\alpha 7 n A C h R$ recorded from cell-attached patches in the presence of $100 \mu \mathrm{M}$ ACh or $10 \mu \mathrm{M}$ Y674-R685. No channel activity was detected at a $1 \mathrm{pM}-100$ $\mu M$ Y674-R685 concentration range. Channel openings are shown as upward deflections.

Membrane potential: $-70 \mathrm{mV}$. Filter: $9 \mathrm{kHz}$.

Given that $\alpha 7$ nAChR activation in the presence of ACh occurs with low open probability as very brief opening events (Fig. $2 \mathrm{~B}$ ), we sought to amplify this effect using a potentiator. PNU120596, a type II positive allosteric modulator (PAM), has been extensively used as a tool in $\alpha 7$ functional studies due to its ability to increase the probability of agonist-elicited channel opening and open-channel durations and to reduce desensitization [29]. We, therefore, examined whether Y674-R685 elicits $\alpha 7$ channel activity in the presence of PNU-120596. Note that by itself, PNU120596 cannot induce channel activation [30].

The macroscopic currents elicited by $1 \mu \mathrm{M}$ Y674-R685 in the presence of $10 \mu \mathrm{M}$ PNU120596 were recorded. Under these conditions, small currents in the low nA order were detected in $30 \%$ of the oocytes tested whereas neither Y674-R685 nor PNU-120596 on their own elicited currents $(n=15, N=3)$ (Fig. 3A).

A

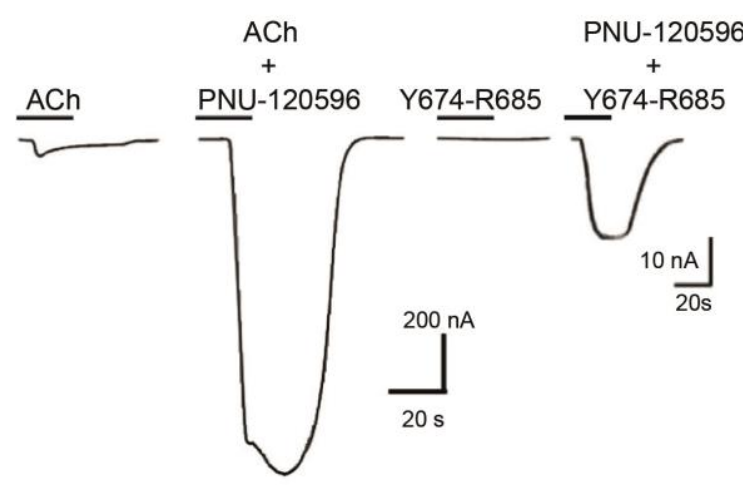

B

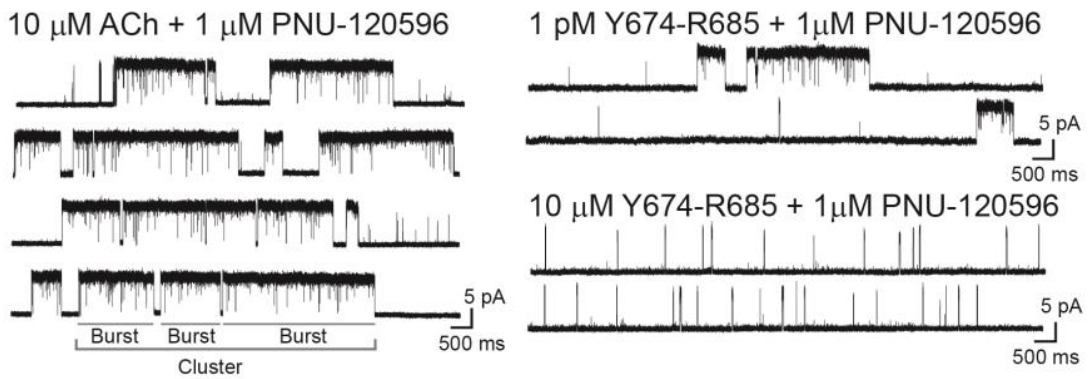

Figure 3. Activation of the human $\alpha 7$ nAChR by Y674-R685 in the presence of the PAM PNU-120596.

A. Macroscopic currents were recorded from oocytes expressing the human $\alpha 7$ nAChR after a pulse of $30 \mu \mathrm{M}$ ACh (control) or $1 \mu \mathrm{M}$ Y674-R685 in the absence or presence of $10 \mu \mathrm{M}$ PNU120596. Current traces shown are representative of $n=15$ recordings from oocytes isolated from $N=3$ donors. 
B. Single-channel currents of the human $\alpha 7$ nAChR in the presence of the type II PAM PNU120596 (1 $\mu \mathrm{M}$ ) activated by $100 \mu \mathrm{M}$ ACh (left), or Y674-R685 at $1 \mathrm{pM}$ or $10 \mu \mathrm{M}$ (right). For each condition typical channel traces are shown. Channel openings are shown as upward deflections. Membrane potential: $-70 \mathrm{mV}$. Filter: $3 \mathrm{kHz}$.

To gain more insights into how Y674-R685 activates $\alpha 7$ nAChRs in the presence of PNU120596, we explored its effects at the single-channel level. ACh-elicited activity in the presence of $1 \mu \mathrm{M}$ PNU-120596 is profoundly different to that in its absence (Fig. 3B). Instead of the brief isolated openings, channel activity shows long periods of high-frequency openings, named clusters, with a mean duration of about $1-3 \mathrm{~s}$ and an amplitude of $10 \mathrm{pA}(-70 \mathrm{mV})$. A cluster corresponds to the activation episode of the same receptor that recovers from desensitization and oscillates between open and closed states before reaching again the more stable non-conducting desensitized state [29]. Clusters are composed of bursts with mean durations of $\sim 300-500 \mathrm{~ms}$, which comprise successive openings separated by very brief closings (Figs. 3B and 4) $[24,29]$.

In the presence of $1 \mu \mathrm{M}$ PNU-120596, Y674-R685 was capable of eliciting channel activity at a wide range of concentrations ( $1 \mathrm{pM}$ to $10 \mu \mathrm{M})$, indicating that this region of the $\mathrm{S}$ protein can activate $\alpha 7 \mathrm{nAChRs} \mathrm{(Fig.} \mathrm{3B).} \mathrm{Since} \mathrm{the} \mathrm{frequency} \mathrm{of} \mathrm{channels} \mathrm{is} \mathrm{variable} \mathrm{among}$ patches due to variations in receptor expression levels, parallel control recordings in the presence of ACh were made. When ACh and PNU-120596 were co-applied, $>98 \%$ of patches showed channel activity (active patches), and the long-duration clusters described above appeared at high frequency as reported before [23] (Fig. 3B). In the presence of PNU-120596 and Y674R685, the percentage of active patches was lower than in the presence of $A C h: 65 \%(n=23, N=4$; $1 \mathrm{pM}$ Y674-R685), 40\% ( $\mathrm{n}=15, \mathrm{~N}=4$; $1 \mathrm{nM}$ Y674-R685), 67\% ( $\mathrm{n}=15, \mathrm{~N}=4 ; 1 \mu \mathrm{M}$ Y674-R685), and $62 \%(n=13, N=3 ; 10 \mu M$ Y674-R685). Also, channel activity evoked by Y674-R685 was much more infrequent and interspaced by long silent periods when compared to that evoked by ACh (Fig. 3B). It is important to note that this type of experiments does not allow for a precise comparison of channel frequency since this parameter may be affected by the variability in the number of receptors in each patch. Nevertheless, at 1 pM Y674-R685, the frequency of channel activation episodes was very low; albeit the active patches showed long clusters resembling those elicited by ACh and PNU-120596 (Figs. 3B and 4).

The increase in Y674-R685 concentration resulted in profound changes in the channel activity pattern, as clearly illustrated in the recordings shown in Fig. 3B. The frequency of opening events appeared to increase, but the duration of the openings and the activation episodes were reduced with increasing concentrations. The typical long-duration clusters were completely absent at Y674-R685 concentrations higher than $1 \mu \mathrm{M}$, at which activation occurred mainly as isolated openings or in short bursts (Fig. 3B and 4).

To define the properties of the activation episodes elicited by the Y674-R685 fragment at different concentrations, the mean durations of openings, bursts, and clusters in the presence of PNU-120596 were determined (Fig. 4). At 1 pM Y674-R685, the mean durations of the longest openings, bursts and clusters were $141 \pm 59 \mathrm{~ms}, 417 \pm 113 \mathrm{~ms}$, and $2330 \pm 673 \mathrm{~ms}$, respectively $(n=3)$. These values were similar to those determined in the presence of $10 \mu \mathrm{M} \mathrm{ACh:} 148 \pm 12 \mathrm{~ms}$ for the slowest open component $(p=0.859, n=3), 550 \pm 38$ ms for bursts $(p=0.125, n=3)$, and 3048 $\pm 516 \mathrm{~ms}$ for clusters $(\mathrm{p}=0.217, \mathrm{n}=3)$, and also comparable to those reported before for $100 \mu \mathrm{M}$ ACh and $1 \mu \mathrm{M}$ PNU-120596 [24,29]. Although the mean durations of clusters were similar at 10 $\mu \mathrm{M}$ ACh and $1 \mathrm{pM}$ Y674-R685, the relative area of the components corresponding to clusters in the histogram was smaller when Y674-R685 was the agonist (relative areas were for $\mathrm{ACh}=0.44$ \pm 0.09 and for $\mathrm{Y} 674-\mathrm{R} 685=0.21 \pm 0.08 ; \mathrm{p}=0.0264$ ) (Fig. 4), indicating a reduction in the frequency of the long activation episodes.

With the increase of Y674-R685 concentration, dwell time distributions for open, bursts and clusters were shifted to briefer durations. The slowest component of each histogram became progressively briefer with increasing Y674-R685 concentrations (Fig. 4). The mean durations 
were $48.2 \pm 13.6 \mathrm{~ms}(1 \mu \mathrm{M}, \mathrm{n}=3)$ and $14.5 \pm 4.3 \mathrm{~ms}(10 \mu \mathrm{M}, \mathrm{n}=4)$ for openings; $70.2 \pm 19.7 \mathrm{~ms}(1$ $\mu \mathrm{M}, \mathrm{n}=3)$ and $20.7 \pm 8.0 \mathrm{~ms}(10 \mu \mathrm{M}, \mathrm{n}=4)$ for bursts; and $104.2 \pm 41.6 \mathrm{~ms}(1 \mu \mathrm{M}, \mathrm{n}=3)$ and $29.9 \pm$ $14.8 \mathrm{~ms}(10 \mu \mathrm{M}, \mathrm{n}=4)$ for clusters. Mean values were statistically significantly different to those determined in the presence of $10 \mu \mathrm{M}$ ACh and $1 \mu \mathrm{M}$ PNU-120596 $(p=0.000665$ and $p=0.00000431$ for open; $p=0.0000403$ and $p=0.00000106$ for burst; $p=0.000597$ and $\mathrm{p}=0.0000681$ for cluster, for 1 and $10 \mu \mathrm{M}$ Y674-R685, respectively). At high Y674-R685 concentrations (e.g., $10 \mu \mathrm{M}$ ), the mean open duration was similar to the mean burst and cluster durations (Fig. 4), indicating that openings occurred mostly in isolation and confirming the lack of the typical long-duration clusters corresponding to potentiated $\alpha 7$ responses.

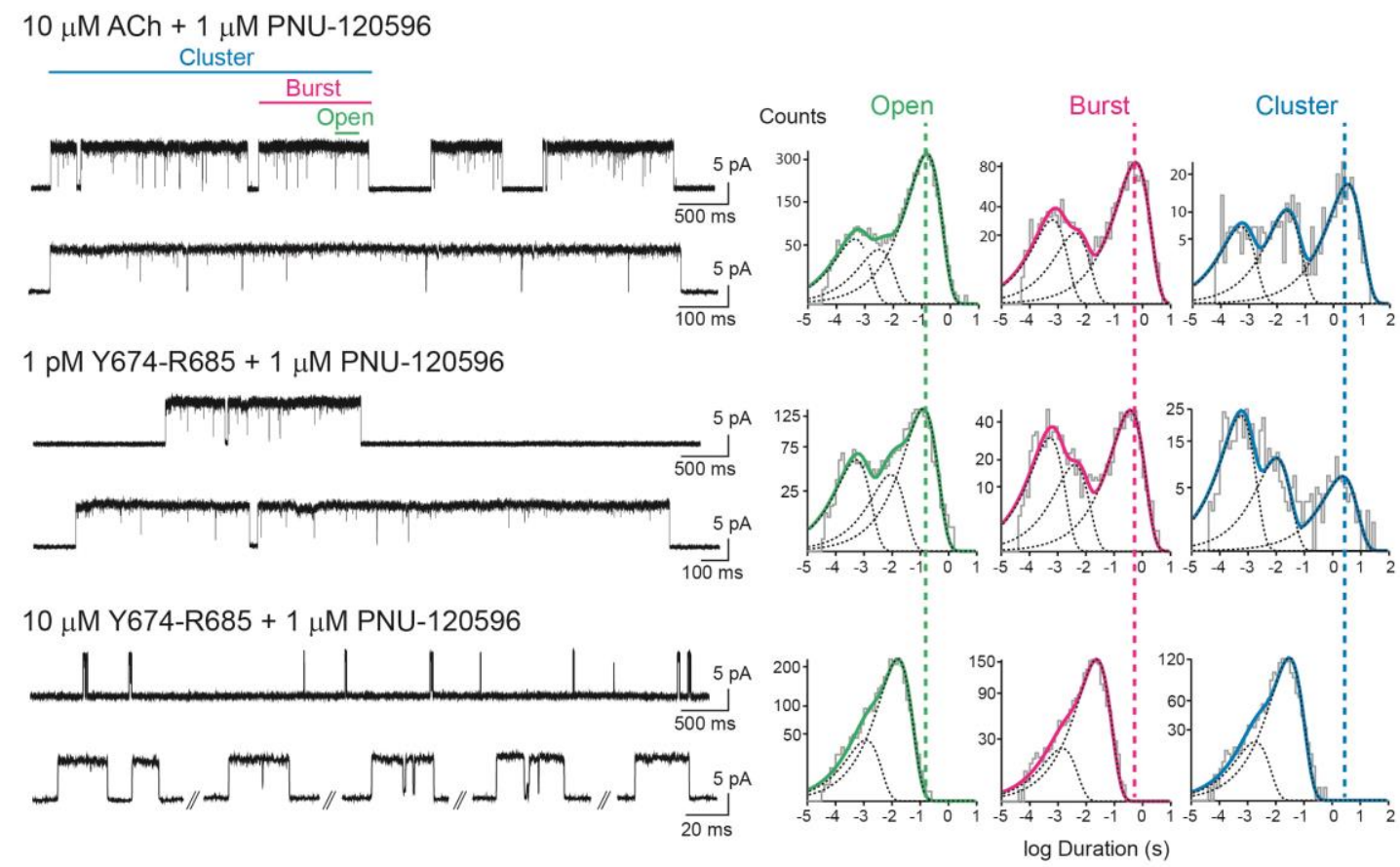

Figure 4. Single-channel recordings of the human $\alpha 7$ nAChR in the presence of Y674-R685.

Single-channel currents of human $\alpha 7$ nAChR in the presence of the type II PAM PNU-120596 $(1 \mu \mathrm{M})$ activated by $100 \mu \mathrm{M}$ ACh, or Y674-R685 at $1 \mathrm{pM}$ or $10 \mu \mathrm{M}$. For each condition, channel traces at two different temporal scales are shown. Channel openings are shown as upward deflections. Representative open, burst and cluster duration histograms are shown for each condition. The open, burst and cluster durations correspond to the durations of the slowest components of each histogram. The dashed lines show how these mean durations change among different conditions. Membrane potential: $-70 \mathrm{mV}$. Filter: $3 \mathrm{kHz}$.

To further confirm that channel activation can be elicited by Y674-R685 in the presence of PNU120596 but not in its absence a different strategy was followed. Single-channel recordings in the presence of different concentrations of the Y674-R685 fragment $(1 \mu \mathrm{M}$ and $10 \mu \mathrm{M})$ were performed. Again, no channel activity was detected in all patches $(n=9, N=2)$. However, the addition of $1 \mu \mathrm{M}$ PNU-120596 to the dish during the course of the recording resulted in the appearance of single-channel activity in most of the silent patches $(83.3 \%$ and $100 \%$ for $1 \mu \mathrm{M}$ $(n=6)$ and $10 \mu M$ Y674-R685 ( $n=3)$, respectively) (Fig. 5). Since this strategy allows comparison of both conditions (with and without PNU-120596) in the same patch, it confirms that activation by 
Y674-R685 requires the PAM. The same strategy applied using ACh as the agonist showed that the typical brief isolated openings are replaced by long-duration clusters after addition of PNU120596 (Fig. 5, [29]). The frequency of opening events was markedly lower, and the durations were briefer at $10 \mu \mathrm{M}$ Y674-R685 with respect to the recordings with ACh (Fig. 5).

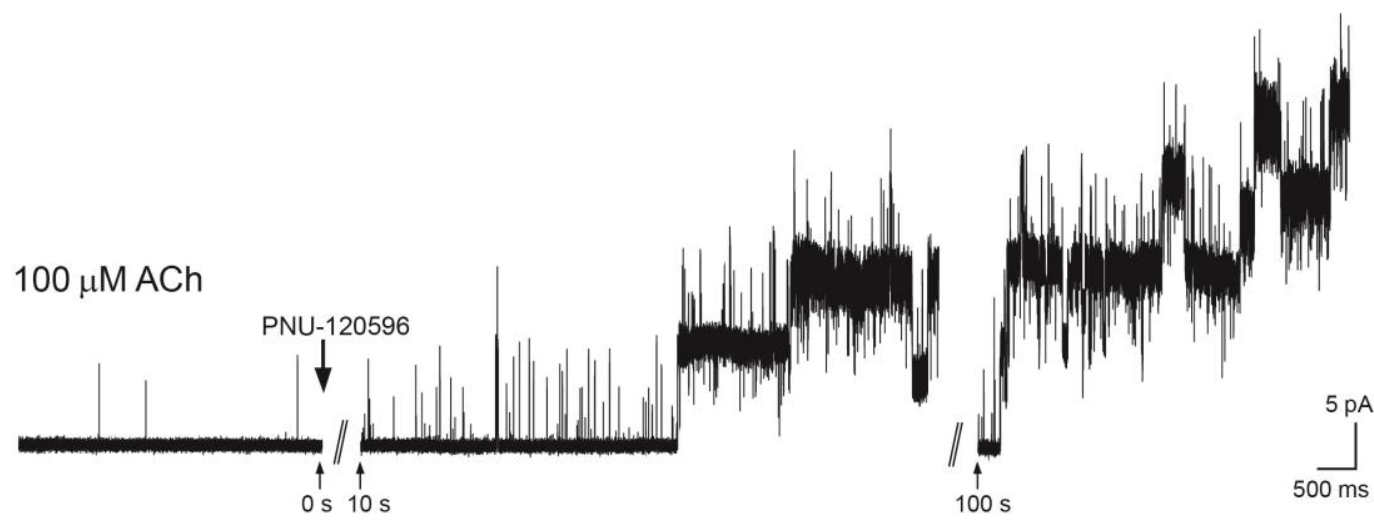

$10 \mu \mathrm{M}$ Y674-R685

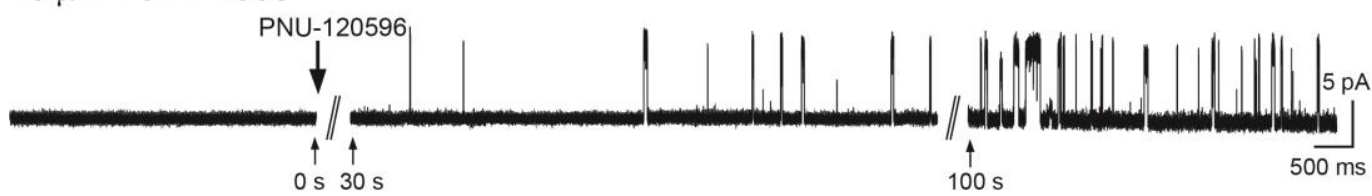

Figure 5. Channel activity elicited by Y674-R685 in the absence or presence of the PAM.

Representative experiments in which channel activity from the same patch was recorded before and after addition of PNU-120596. ACh or $10 \mu M$ Y674-R685 were present in the pipette solution. The indicated time corresponds to the time of recording after addition of PNU-120596.

Top: Single-channel currents of human $\alpha 7$ activated by $100 \mu \mathrm{M}$ ACh appeared mainly as brief isolated openings. Addition of $1 \mu \mathrm{M}$ PNU-120596 to the extracellular solution surrounding a cellattached patch resulted in a marked increase in current in the continued presence of $100 \mu \mathrm{M} \mathrm{ACh}$ in the patch pipette. This experiment is representative of 4 different patches.

Bottom: Channel activity was undetectable in the presence of Y674-R685. Addition of $1 \mu M$ PNU120596 to the extracellular solution surrounding the silent patch revealed channel activity, indicating that only in the presence of the PAM $10 \mu M$ Y674-R685 can activate $\alpha 7$. This experiment is representative of 3 different patches.

Channel openings are shown as upward deflections. Membrane potential: $-70 \mathrm{mV}$. Filter $3 \mathrm{kHz}$.

Together, these results confirm that Y674-R685 functionally interacts with the $\alpha 7 \mathrm{nAChR}$. They also show that Y674-R685 acts as a very low-efficacy agonist since channel opening requires the presence of PNU-120596 and occurs with low probability, and that the increase in concentration is accompanied by a decrease in the duration of open channel lifetime and of the activation episodes.

Because PNU-120596 is a highly efficacious type II PAM with the capability of recovering receptors from desensitization, we also tested if Y674-R685 elicited channel activity in the presence of 5-hydroxyindole $(5-\mathrm{HI})$, a type I PAM. This compound induces potentiation with lower efficacy than PNU-120596 and does not recover receptors from desensitization [22,24,31]. In the presence of $2 \mathrm{mM} 5-\mathrm{HI}, 100 \mu \mathrm{M}$ ACh elicited prolonged openings and bursts composed of successive openings which lasted about $4 \mathrm{~ms}$ (Fig. 6). The histograms showed that the duration of the slowest open component was 4-fold longer ( $1.28 \pm 0.35 \mathrm{~ms}, n=37$, versus $0.30 \pm 0.06 \mathrm{~ms}$, $\mathrm{n}=38$ ) and the mean burst duration was 8 -fold longer ( $3.60 \pm 1.29 \mathrm{~ms}, \mathrm{n}=37$, versus $0.46 \pm 0.12$ 
$\mathrm{ms}, \mathrm{n}=38$ ) than in the absence of the PAM. Replacing ACh by Y674-R685 ( $1 \mathrm{pM}$ or $10 \mu \mathrm{M})$ revealed $\alpha 7$ channel activity. However, the frequency of opening events was markedly lower when compared to that elicited by ACh; only few events were detected during a 15-min recording period (Fig. 6). At $1 \mathrm{pM}$ Y674-R685, 83.3\% of the patches showed $\alpha 7$ channel activity, but the frequency of openings was very low $(n=18, N=3)$. We therefore combined all recordings for constructing open and burst duration histograms. The resulting mean open and burst durations were $1.11 \mathrm{~ms}$ and $4.25 \mathrm{~ms}$, respectively (Supplementary Fig. 2). At $10 \mu \mathrm{M}$ Y674-R685, the frequency of channel openings was higher than at $1 \mathrm{pM}$ but still lower than that elicited by ACh. The mean open and burst durations were $0.73 \pm 0.07 \mathrm{~ms}$ and $0.85 \pm 0.13 \mathrm{~ms}(\mathrm{n}=3)$, respectively. Both mean durations were statistically significantly briefer than the corresponding ones in the presence of $\mathrm{ACh}$ and $2 \mathrm{mM} \mathrm{5-HI}(\mathrm{p}=0.0114$ and 0.005 for mean open and mean burst durations, respectively). Also, the observation that in the presence of $2 \mathrm{mM} 5-\mathrm{HI}$ and $10 \mu \mathrm{M} \mathrm{Y} 674-\mathrm{R} 685$ the mean duration of openings was similar to that of bursts indicates that at high fragment concentrations channel openings occurred mainly as isolated events instead of in quick succession forming activation episodes, as described before for recordings with the type II PAM PNU-120596.

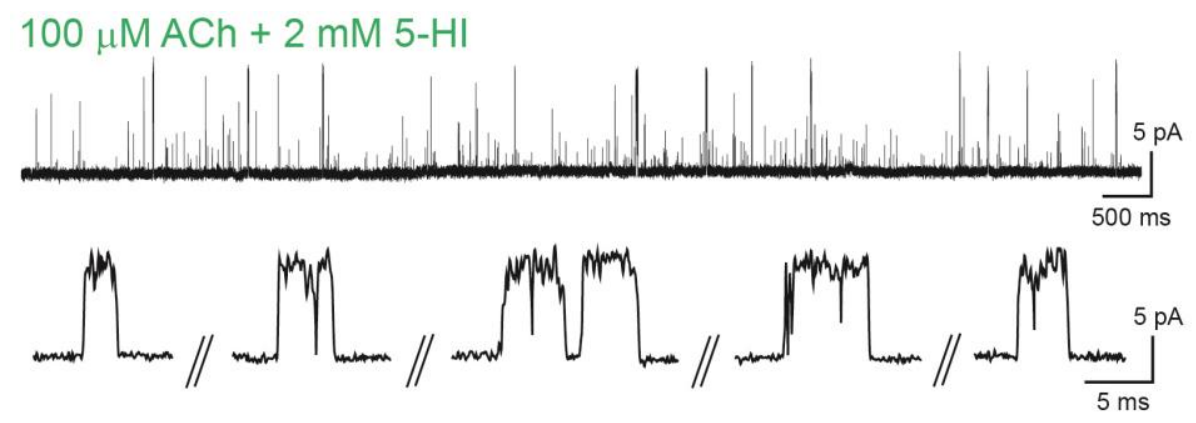

$10 \mu \mathrm{M}$ Y674-R685 + 2 mM 5-HI
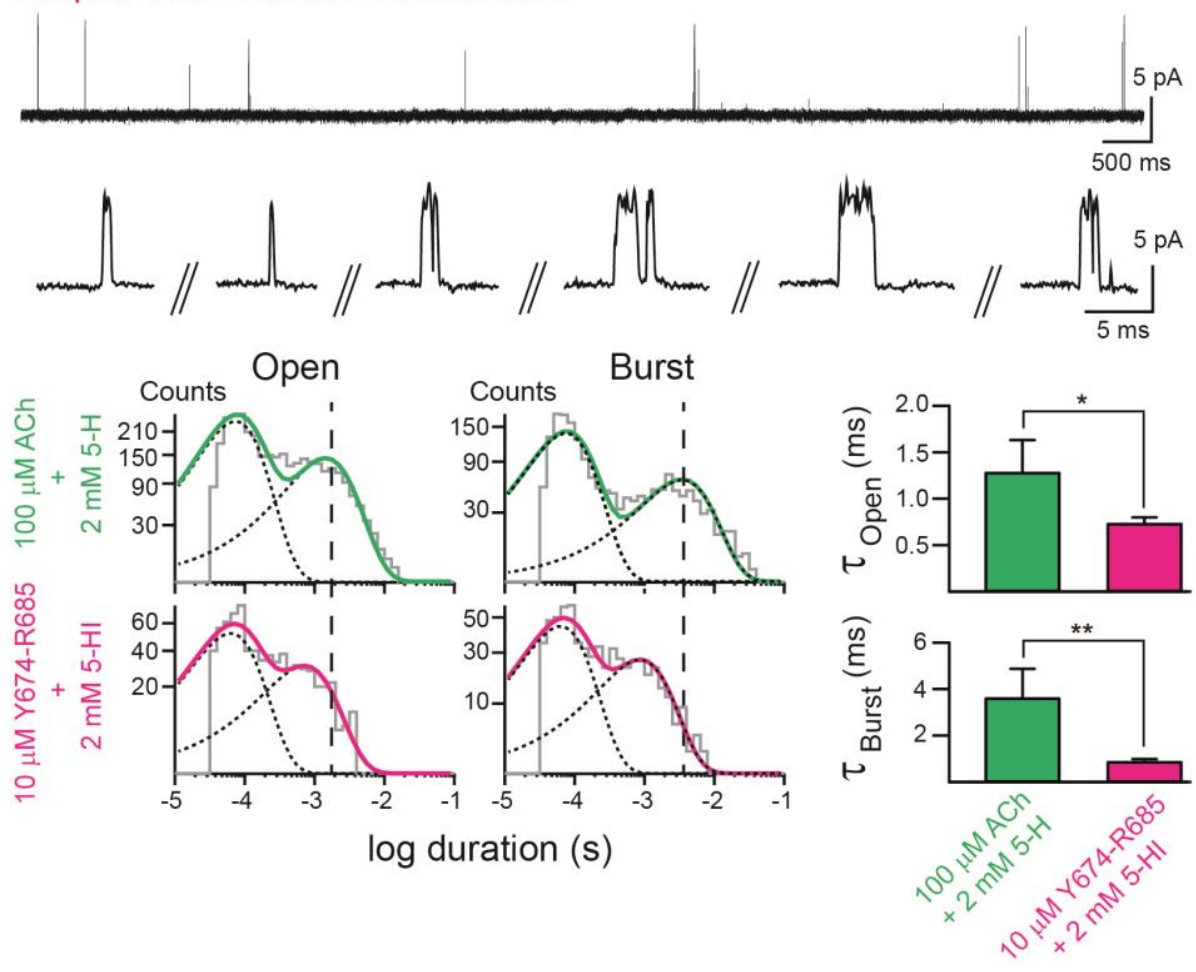
Figure 6. Activation of the human a7 nAChR by Y674-R685 in the presence of the type I PAM, 5-HI.

Single-channel currents were recorded from cells expressing the human $\alpha 7 n A C h R$ in the presence of $2 \mathrm{mM} 5-\mathrm{HI}$ as the PAM and $100 \mu \mathrm{M}$ ACh or $10 \mu \mathrm{M}$ Y674-R685 as agonists. Traces at two different scales are shown for each condition. Membrane potential: $-70 \mathrm{mV}$, Filter: $9 \mathrm{kHz}$. Representative open and burst duration histograms are shown for each agonist. The bar chart shows the mean durations of open and bursts for each agonist ( $n=37$ for ACh, and $n=3$ for Y674R685). ${ }^{*} p<0.05,{ }^{* *} p<0.01$.

\section{Inhibition of $\alpha 7$ activity by Y674-R685 from S protein}

To understand the molecular mechanisms driving the inhibitory effects of Y674-R685 evidenced by the dramatic decrease in open durations, we evaluated Y674-R685 effects on $\alpha 7$ activated by $10 \mu \mathrm{M}$ ACh (Fig. 7A). Given the very brief open duration of $\alpha 7$ channels, which is close to the time resolution of our system, we included PNU-120596 to better quantify the decrease in open durations.

Whereas in the presence of $1 \mu \mathrm{M}$ PNU-120596, $10 \mu \mathrm{M}$ ACh led to an activation pattern composed of long clusters as described above, the inclusion of Y674-R685 produced marked changes in this pattern in a concentration-dependent manner. Y674-R685 produced an inhibitory effect even at a concentration as low as $1 \mathrm{pM}$ (Fig. 7A and Supplementary Table 1). The results showed that the cluster duration was the most sensitive parameter. With respect to the control

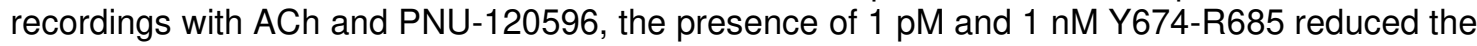
cluster duration $72 \%$ and $78 \%$, respectively, and the open duration $54 \%$ and $57 \%$, respectively (Fig. 7A, Supplementary Table 1). As the concentration increased, the inhibition was more evident and at $10 \mu \mathrm{M}$ Y674-R685, the long durations clusters were absent, and only markedly briefer bursts were detected (Fig. 7A and Supplementary Table 1). At this high concentration, the mean duration of the slowest open component was $9.9 \pm 2.6 \mathrm{~ms}(n=4)$, which corresponds to about $7 \%$ of the control open duration. Also, the open duration was not different from the mean burst duration (11.2 $\pm 3.0 \mathrm{~ms}, \mathrm{n}=4$ ), indicating that most long openings occurred in isolation (Supplementary Table 1). Although clusters were not visually detected, we constructed cluster duration histograms using a critical time for cluster resolution between 10 and $20 \mathrm{~ms}$, which is about 20 to 40 -fold times longer than that used for burst-duration histograms. The mean duration of the slowest component of the cluster histogram was $14.1 \pm 4.4 \mathrm{~ms}(n=4)$, which was similar to that of bursts, thus confirming the lack of the long-duration activation episodes occurring in potentiated $\alpha 7$ channels in the presence of $10 \mu \mathrm{M}$ Y674-R685 (Fig. 7a, Supplementary Table 1). 
A
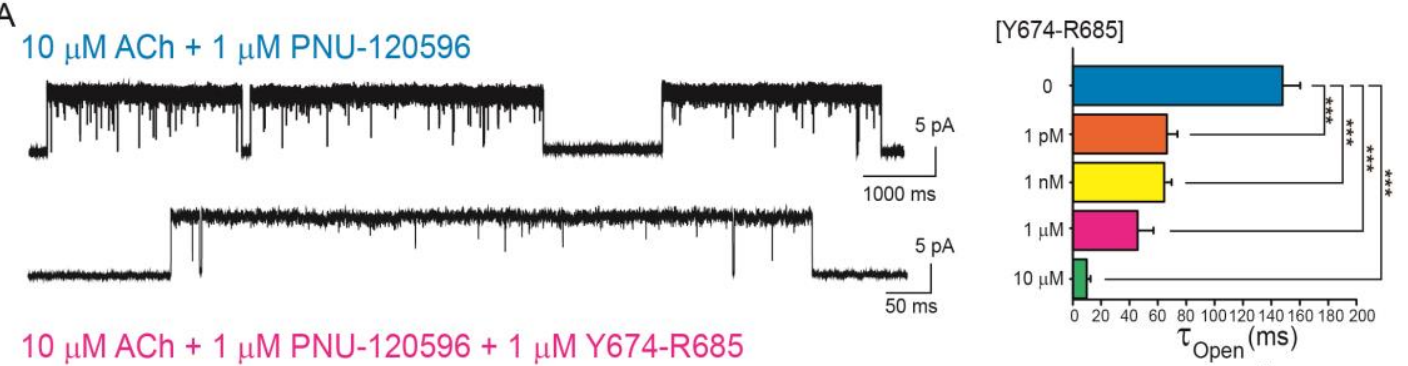

$10 \mu \mathrm{M} \mathrm{ACh}+1 \mu \mathrm{M}$ PNU-120596 + $1 \mu \mathrm{M}$ Y674-R685
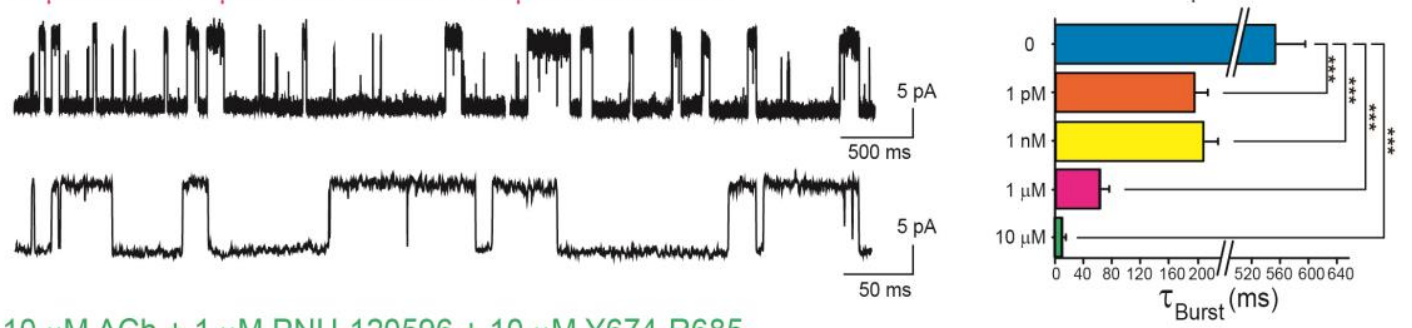

$10 \mu \mathrm{M}$ ACh + $1 \mu \mathrm{M}$ PNU-120596 + $10 \mu \mathrm{M}$ Y674-R685
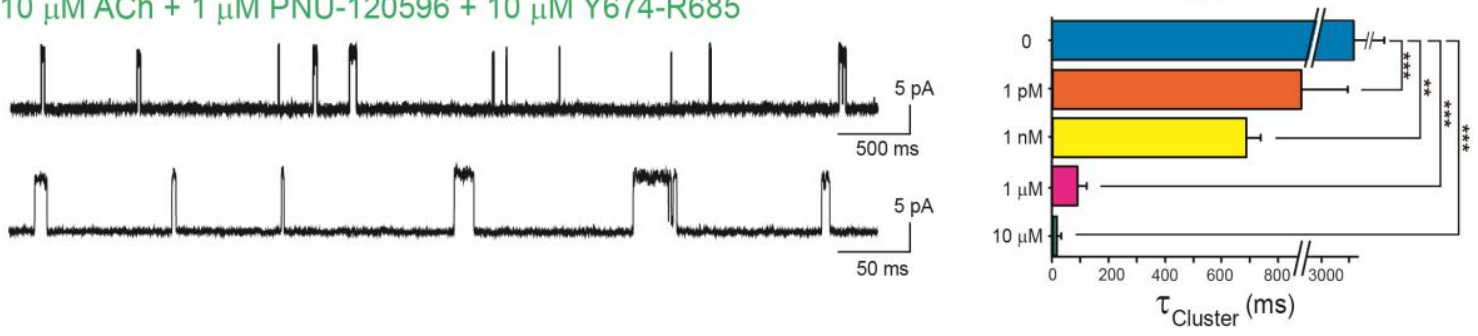

B
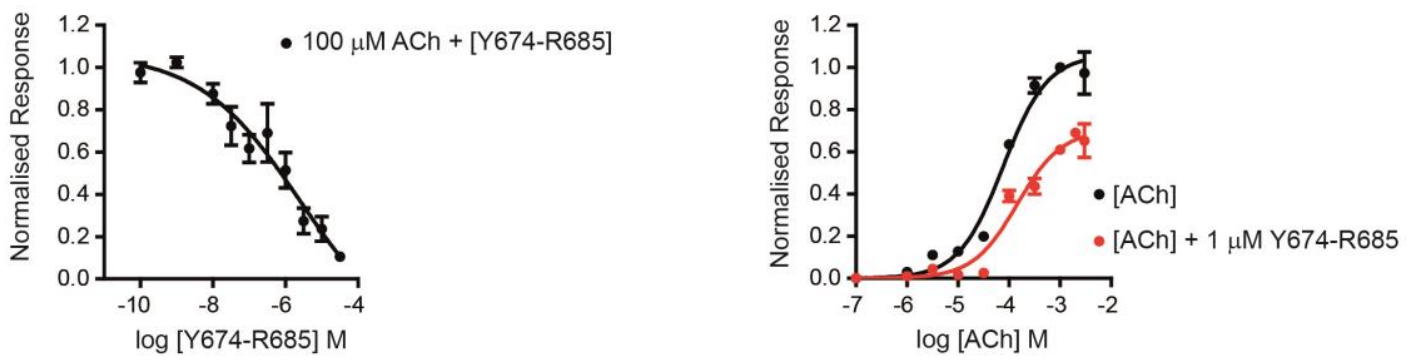

Figure 7. Y674-R685 Inhibition of a7 nAChR channels activated by ACh.

A. Single-channel currents elicited by $10 \mu M$ ACh and potentiated by $1 \mu M$ PNU-120596 were recorded in the absence (control) or presence of 1 or $10 \mu \mathrm{M}$ Y674-R685.

Left: Typical channel traces are shown at two different temporal scales. Channel openings are shown as upward deflections. Membrane potential: $-70 \mathrm{mV}$. Filter: $3 \mathrm{kHz}$.

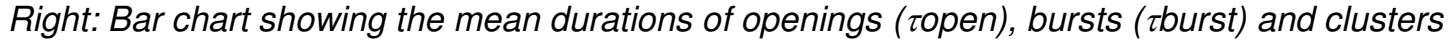
( $\tau$ cluster) in the absence and in the presence of $1 \mathrm{pM}, 1 \mathrm{nM}, 1 \mu \mathrm{M}$ and $10 \mu \mathrm{M}$ Y674-R685. ${ }^{* *} p<0.01,{ }^{* * *} p<0.001$ (Student-t Test) (Supplementary Table 1).

B. Left Panel: Concentration response curve (CRC) for the inhibition of the $\alpha 7 n A C h R$ by Y674R685. Increasing concentrations of Y674-R685 (0.1 nM to $30 \mu \mathrm{M})$ were co-applied with control ACh $(100 \mu \mathrm{M})$. Responses were measured fom the peak of ACh-elicited currents. Each data point represents the average normalized response of six cells ( \pm SEM).

Right Panel: Competition CRC data (red) for $1 \mu \mathrm{M}$ Y674-R685 co-applied with different ACh concentrations (0.1-2000 $\mu \mathrm{M}$ ). For comparison, ACh CRC data alone (black) are shown at the same concentrations. Data were fitted with the Hill equation, as described in Methods. Data points represent the average normalized response of six oocytes ( \pm SEM). 
To gain further insight into the mechanism driving the inhibitory effect of Y674-R685 in the presence of ACh and PNU-120596, we compared the pattern of channel activity when methyllycaconitine (MLA), a reversible competitive $\alpha 7$ antagonist [16], was present instead of the $S$ fragment. To better assess the impact of MLA, we used the strategy of filling the tip of the pipette with the buffer solution containing $10 \mu \mathrm{M}$ ACh and $1 \mu \mathrm{M}$ PNU-120596 and the shaft with the same solution but including MLA (100 nM). This strategy allowed following in real-time the effects of the antagonist during the recording of ACh-activated channels. While at the beginning of the recording the typical pattern comprising high-frequency channel activity and long duration clusters was observed, channel activity decreased over time and was completely suppressed after about 10-15 min due to the presence of MLA (Supplementary Fig. 3, $n=3$ ). No reduction in the duration of clusters or bursts, as described in the presence of Y674-R685, was detected in the presence of MLA (Supplementary Fig. 3). Thus, the type of inhibition mediated by Y674-R685 differs from that produced by the competitive antagonist.

The results together suggest that the Y674-R685 region of the $S$ protein acts as a noncompetitive antagonist of $\alpha 7$. To further confirm this result, we determined the effects of Y674R685 on the peak current responses evoked by an approximate $E_{50}$ concentration of ACh (100 $\mu \mathrm{M})$. Application of Y674-R685 with ACh inhibited peak currents, with an $\mathrm{IC}_{50}$ of $1.8 \pm 0.8 \mu \mathrm{M}(\mathrm{n}=$ 10), but inhibition was not complete (Fig. 7B). We then investigated whether the observed antagonism was competitive or not. For these studies, $1 \mu \mathrm{M}$ Y674-R685 was co-applied with increasing concentrations of ACh (0.1- $2000 \mu \mathrm{M})$ (Fig. 7B). Compared to ACh alone, Y674-R685 co-application affected ACh efficacy, reducing the maximal currents elicited by ACh (Imax) by 30 $\pm 4 \%(n=6)$ and slightly affecting its potency $\left(E_{50}=80 \pm 6 \mu M\right.$ and $\left.131 \pm 92 \mu M\right)(n=6)$. These results confirm the non-competitive antagonism of ACh responses by Y674-R685. 


\section{DISCUSSION}

The S protein from SARS-CoV-2 contains a sequence motif (region Y674-R685) homologous to motifs present in nAChR antagonists, such as a-bungarotoxin from Bungarus multicinctus, and in the glycoprotein of rabies virus, which suggested that these receptors may play a role in the pathophysiology of COVID-19 [6,7]. Subsequent MD simulations support a possible interaction between the accessible Y674-R685 region of the SARS-CoV-2 S protein and nAChRs [8].

Here, we provide the first molecular evidence of a direct functional interaction between human $\alpha 7$ nAChR and the Y674-R685 region of the SARS-CoV-2 S protein. This interaction, which takes place within the picomolar to micromolar concentration range, results in a dual effect involving low efficacious agonism and non-competitive antagonism.

$\alpha 7$ is a homomeric nAChR highly expressed in both neuronal and non-neuronal cells, which is emerging as a potential drug target for neurological, neurodegenerative, and inflammatory disorders [32-34]. It responds to ACh by opening an intrinsic ion channel permeable to cations, triggering rapid membrane depolarization and calcium influx [35]. $\alpha 7$ activation is unique as it shows the most rapid desensitization and the highest calcium permeability of the family [36]. Although indirect crosstalk may occur [11], determining a direct functional interaction between SARS-CoV-2 S protein and the $\alpha 7 \mathrm{nAChR}$ is the cornerstone for supporting the hypothesis related to the involvement of this receptor in the COVID-19 inflammatory disease. Here, by taking advantage of the power of single-channel recordings, we provide novel information regarding the molecular functional effects and the underlying mechanisms of the interaction between the $\alpha 7 \mathrm{nAChR}$ and the Y674-R685 region of the SARS-CoV-2 S protein.

We found that Y674-R685 activates the $\alpha 7$ receptor at picomolar concentrations but with exceptionally low efficacy. The efficacy for activation is so low that only in the presence of PAMs channel activity can be detected, and, even in their presence, the frequency of channel activity induced by the fragment is markedly lower than the one elicited by ACh. In addition, ACh-elicited responses are reduced by the $S$ protein fragment, indicating a dual function as agonist and inhibitor. Given that endogenous $\alpha 7$ PAMs, with the exception of calcium, have not been reported so far, the S protein may physiologically play an inhibitory role at $\alpha 7 . \alpha 7 \mathrm{nAChR}$ also mediates metabotropic responses, which include release of calcium from intracellular stores induced by the calcium influx and the triggering of signal transduction pathways $[14,35,37,38]$. This raises important questions regarding how these metabotropic responses are modified by the $S$ protein and their impact on COVID-19 pathophysiology. Interestingly, the neurotoxin-like region in the rabies virus glycoprotein as well as the full length ectodomain of the glycoprotein inhibit macroscopic responses of $\alpha 4 \beta 2 \mathrm{nAChRs}$ in the mid-micromolar range. The fragment also mediates in vivo effects in mice and Caenorhabditis elegans [10].

PAMs, which reduce the energy barrier for activation, are emerging as novel therapeutic tools for neurological, neurodegenerative, and inflammatory disorders as they potentiate $\alpha 7$ responses in the presence of an agonist $[32,33,39,40]$. They have been classified as type I PAMs, which enhance agonist-induced macroscopic currents, and type II PAMs, that also delay desensitization and recover receptors from desensitized states [24,41,42]. At the single channel level, PAMs enhance open channel durations and induce activation in episodes in which the channel oscillates between open and closed conformations, thus generating an activity pattern markedly different from the isolated submillisecond-openings in the absence of PAMs [24]. Depending on the type and efficacy of the PAM, the potentiated activation episodes can range from milliseconds (as shown here for 5-HI) to seconds (as demonstrated here for PNU-120596). Despite the marked differences between 5-HI and PNU-120596 regarding their efficacy for potentiation and influence on receptor desensitization, Y674-R685 activates the $\alpha 7 \mathrm{nAChR}$ in the presence of both PAMs but not in their absence, indicating its action as a low-efficacy agonist. Also, in the presence of both PAMs, reduction in the duration of the opening events with 
increasing Y674-R685 concentration is observed, thus supporting the additional role of this fragment as an $\alpha 7$ inhibitor.

At 1 pM Y674-R685, channel activity in the presence of PNU-120596 is markedly infrequent but kinetically indistinguishable from the ACh-elicited one. The open channel lifetime, and the architecture and duration of the activation episodes (clusters) are similar in the presence of ACh or $1 \mathrm{pM} \mathrm{Y674-R685.} \mathrm{As} \mathrm{the} \mathrm{Y674-R685} \mathrm{concentration} \mathrm{increases,} \mathrm{the} \mathrm{frequency} \mathrm{of} \mathrm{opening}$ events increases, but their durations become progressively briefer and long-duration clusters are not detected. This inhibitory effect was confirmed by experiments in which ACh was the agonist, clearly showing a concentration-dependent reduction of open and cluster durations by the Y674R685 fragment. To determine if this modified channel activity pattern was similar to that observed in the presence of a reversible competitive antagonist, we also explored how MLA affected $\alpha 7$ potentiated channels. The results showed that the type of channel inhibition was completely different, suggesting different mechanisms. The classical pharmacological experiments using dose-response curves from macroscopic current recordings support a mechanism of noncompetitive inhibition exerted by the $S$ protein fragment.

The ability to act as a low-efficacy agonist is consistent with data from our MD simulations predicting that Y674-R685 can bind directly to the agonist binding site located in the extracellular domain of the $\alpha 7 \mathrm{nAChR}$, leading in some conformations to a semi-capped loop C [8]. Loop $C$ is one of the three loops that form the principal face of the orthosteric binding site [43]. Upon agonist binding, loop $\mathrm{C}$ closes to cap the agonist, an event associated with priming and channel opening [44]. Loop C capping aids the anchoring of the bound agonist to the orthosteric binding site. It has also been suggested that agonists induce more compact loop conformations, while partial agonists and antagonists produce incomplete closure or prevent loop C capping [45-47].

Our previous MD simulations of Y674-R685 bound to the $\alpha 7 \mathrm{nAChR}$ identified the guanidinium group of R682 in the SARS-COV-2 S protein as the key anchoring point to the $\alpha 7$ nAChR (Fig. 1C), forming strong interactions with several residues lining the receptor's ligand binding pocket [8]. These simulations also show that, when bound to $\alpha 7$, the Y674-R685 region of the SARS-CoV-2 S protein adopts many different conformations within the binding pocket, ranging from highly compact to fully extended configurations (Supplementary Fig. 4). Some of these binding modes allow for the formation of the key interactions necessary to activate the receptor (Fig. 1C), while others do not (Supplementary Fig. 5) [8]. Although the $\alpha 7 \mathrm{nAChR}$ has five identical orthosteric binding sites, agonist occupancy of only one is required to elicit channel activation [26]. Thus, it could be possible that the Y674-R685 fragment occupancy of the binding sites in multiple orientations, some of which cannot trigger activation, may contribute to its low efficacy, as described before for partial agonists [46]. Alternatively, the partial closure of loop $C$ in the presence of the Y674-R685 [8] observed in some of our previous simulations may also reduce the efficacy for channel opening (Supplementary Fig. 6).

As shown here for Y674-R685, several compounds of different structures have dual opposite effects on nAChRs, including $\alpha 7$, by acting as agonists and non-competitive antagonists (also called negative allosteric modulators, NAMs) [23,48,49]. NAMs comprise a wide range of structurally different compounds that inhibit receptor function by binding to sites distinct to the orthosteric sites (allosteric) [40]. These allosteric sites may be located in different receptor domains, including the extracellular [50] and transmembrane domains [29,51]. The site from which Y674-R685 exerts inhibition as well as the precise mechanism remain to be determined. Non-competitive inhibition of channel activity may occur through enhanced desensitization, impaired opening, destabilization of the open state, channel blockade. We discard open-channel block since it is improbable that this region enters into the pore and also, fast flickering, typical of fast open-channel blockers, was not observed [52]. Future competitive binding assays as well as experiments with mutant receptors will be useful to clearly identify the binding sites.

Overall, our results reveal a functional interaction between the Y674-R685 region of the SARS-CoV-2 S protein and the $\alpha 7 \mathrm{nAChR}$, with the predominant effect probably being inhibitory 
since activation cannot occur in the absence of PAMs. Although too speculative at this stage, this finding raises the possibility that the hyper-inflammatory response observed in some COVID-19 patients may be partly due to inhibition of $\alpha 7 \mathrm{nAChRs}$. It has been shown that activation of $\alpha 7$ $\mathrm{nAChR}$ in the immune system protects from excessive production of pro-inflammatory cytokines (e.g., TNF- $\alpha$ ) [13]. Impairment of this receptor subtype results in an overproduction of cytokines and enhanced tissue damage [53]. In this context, therapeutic interventions focused on $\alpha 7$ nAChR may be valuable to be explored. 


\section{REFERENCES}

1. Casalino L, Gaieb Z, Goldsmith JA et al (2020) Beyond shielding: the roles of glycans in the SARS-CoV-2 spike protein. ACS Cent Sci 6 1722-1734. https://doi.org/10.1021/acscentsci.0c01056

2. Yan R, Zhang Y, Li Y et al (2020) Structural basis for the recognition of SARS-CoV-2 by fulllength human ACE2. Science 367(6485) 1444-1448. https://doi.org/10.1126/science.abb2762

3. Hoffmann M, Kleine-Weber H, Schroeder S et al (2020) SARS-CoV-2 Cell Entry Depends on ACE2 and TMPRSS2 and Is Blocked by a Clinically Proven Protease Inhibitor. Cell 181(2) 271-280.e8. https://doi.org/10.1016/j.cell.2020.02.052

4. Daly JL, Simonetti B, Klein K et al (2020) Neuropilin-1 is a host factor for SARS-CoV-2 infection. Science 370(6518) 861-865. https://doi.org/10.1126/science.abd3072

5. Cantuti-Castelvetri L, Ojha R, Pedro LD et al (2020) Neuropilin-1 facilitates SARS-CoV-2 cell entry and infectivity. Science 370(6518) 856-860. https://doi.org/10.1126/science.abd2985

6. Changeux JP, Amoura Z, Rey FA, Miyara M (2020) A nicotinic hypothesis for Covid-19 with preventive and therapeutic implications. Comptes rendus biologies 343(1) 33-39. https://doi.org/10.5802/crbiol.8

7. Farsalinos K, Eliopoulos E, Leonidas DD et al (2020) Nicotinic Cholinergic System and COVID-19: In Silico Identification of an Interaction between SARS-CoV-2 and Nicotinic Receptors with Potential Therapeutic Targeting Implications. International journal of molecular sciences 21(16) 5807. https://doi.org/10.3390/iims21165807

8. Oliveira A, Ibarra AA, Bermudez I et al (2021) A potential interaction between the SARS-CoV2 spike protein and nicotinic acetylcholine receptors. Biophysical journal 120(6) 983-993. https://doi.org/10.1016/j.bpj.2021.01.037

9. Grant SN, Lester H (2021) Regulation of epithelial sodium channel activity by SARS-CoV-1 and SARS-CoV-2 proteins. Biophysical journal 120(14) 2805-2813. https://doi.org/10.1016/j.bpj.2021.06.005

10. Hueffer K, Khatri S, Rideout S, et al (2017) Rabies virus modifies host behaviour through a snake-toxin like region of its glycoprotein that inhibits neurotransmitter receptors in the CNS. Scientific reports 7(1) 12818. https://doi.org/10.1038/s41598-017-12726-4

11. Russo P, Bonassi S, Giacconi R et al (2020) COVID-19 and smoking: is nicotine the hidden link? The European respiratory journal 55(6) 2001116. https://doi.org/10.1183/13993003.01116-2020

12. Wang H, Yu M, Ochani $\mathrm{M}$ et al (2003) Nicotinic acetylcholine receptor alpha7 subunit is an essential regulator of inflammation. Nature 421(6921) 384-388. https://doi.org/10.1038/nature01339

13. Rosas-Ballina M, Ochani M, Parrish WR et al (2008) Splenic nerve is required for cholinergic antiinflammatory pathway control of TNF in endotoxemia. Proceedings of the National Academy of Sciences of the United States of America 105(31) 11008-11013. https://doi.org/10.1073/pnas.0803237105

14. Egea J, Buendia I, Parada E et al (2015) Anti-inflammatory role of microglial alpha7 nAChRs and its role in neuroprotection. Biochemical pharmacology 97(4) 463-472. https://doi.org/10.1016/j.bcp.2015.07.032

15. Pinheiro NM, Santana FP, Almeida RR et al (2017) Acute lung injury is reduced by the a7nAChR agonist PNU-282987 through changes in the macrophage profile. FASEB journal: official publication of the Federation of American Societies for Experimental Biology 31(1) 320-332. https://doi.org/10.1096/fj.201600431R

16. Wonnacott S (2014), Nicotinic ACh Receptors. Tocris Bioscience Scientific Reviews Series $1-31$.

17. Nau J, Luthra P, Lanzer $\mathrm{K}$ et al (2021) Varenicline prevents SARS-CoV-2 infection in vitro and in Rhesus Macaques. bioRxiv [Preprint]. https://doi.org/10.1101/2021.06.29.450426 (accessed 20 September 2021) 
18. Bouzat C, Bren N, Sine SM (1994) Structural basis of the different gating kinetics of fetal and adult nicotinic acetylcholine receptors. Neuron 13 1395-1402. https://doi.org/10.1016/08966273(94)90424-3

19. Chrestia JF, Bruzzone A, Esandi M, Bouzat C (2021) Tyrosine phosphorylation differentially fine-tunes ionotropic and metabotropic responses of human $\alpha 7$ nicotinic acetylcholine receptor. Cellular and molecular life sciences: CMLS, 78(13) 5381-5395. https://doi.org/10.1007/s00018-021-03853-3

20. Lansdell SJ, Gee VJ, Harkness PC et al (2005) RIC-3 enhances functional expression of multiple nicotinic acetylcholine receptor subtypes in mammalian cells. Molecular pharmacology 68(5) 1431-1438. https://doi.org/10.1124/mol.105.017459

21. Gu S, Matta JA, Lord B et al (2016) Brain a7 Nicotinic Acetylcholine Receptor Assembly Requires NACHO. Neuron 89(5) 948-955. https://doi.org/10.1016/i.neuron.2016.01.018

22. Nielsen E, Bermudez I, Bouzat C (2019) Flavonoids as positive allosteric modulators of $\alpha 7$ nicotinic receptors. Neuropharmacology 160107794. https://doi.org/10.1016/j.neuropharm.2019.107794

23. Lasala M, Fabiani C, Corradi J, Antollini S, Bouzat C (2019) Molecular Modulation of Human $\alpha 7$ Nicotinic Receptor by Amyloid- $\beta$ Peptides. Frontiers in cellular neuroscience 1337 . https://doi.org/10.3389/fncel.2019.00037

24. Andersen ND, Nielsen BE, Corradi $\mathrm{J}$ et al (2016) Exploring the positive allosteric modulation of human $\alpha 7$ nicotinic receptors from a single-channel perspective. Neuropharmacology 107 189-200. https://doi.org/10.1016/j.neuropharm.2016.02.032

25. Bouzat C, Bartos M, Corradi J, Sine SM (2008) The interface between extracellular and transmembrane domains of homomeric Cys-loop receptors governs open-channel lifetime and rate of desensitization. The Journal of neuroscience: the official journal of the Society for Neuroscience 28(31) 7808-7819. https://doi.org/10.1523/JNEUROSCI.0448-08.2008

26. Andersen N, Corradi J, Sine SM, Bouzat C (2013) Stoichiometry for activation of neuronal $\alpha 7$ nicotinic receptors. Proceedings of the National Academy of Sciences of the United States of America 110(51) 20819-20824. https://doi.org/10.1073/pnas.1315775110

27. Minguez-Viñas T, Nielsen BE, Shoemark DK et al (2021) A conserved arginine with nonconserved function is a key determinant of agonist selectivity in $\alpha 7$ nicotinic $\mathrm{ACh}$ receptors. British journal of pharmacology 178(7) 1651-1668. https://doi.org/10.1111/bph.15389

28. Nielsen BE, Minguez T, Bermudez I, Bouzat C (2018) Molecular function of the novel $\alpha 7 \beta 2$ nicotinic receptor. Cellular and molecular life sciences: CMLS 75(13) 2457-2471. https://doi.org/10.1007/s00018-017-2741-4

29. daCosta CJ, Free CR, Corradi J, Bouzat C, Sine SM (2011) Single-channel and structural foundations of neuronal $\alpha 7$ acetylcholine receptor potentiation. The Journal of neuroscience: the official journal of the Society for Neuroscience, 31(39) 13870-13879. https://doi.org/10.1523/JNEUROSCI.2652-11.2011

30. Hurst RS, Hajós M, Raggenbass M et al (2005) A novel positive allosteric modulator of the alpha7 neuronal nicotinic acetylcholine receptor: in vitro and in vivo characterization. The Journal of neuroscience: the official journal of the Society for Neuroscience 25(17) 43964405. https://doi.org/10.1523/JNEUROSCI.5269-04.2005

31. Zwart R, De Filippi G, Broad LM et al (2002) 5-Hydroxyindole potentiates human alpha 7 nicotinic receptor-mediated responses and enhances acetylcholine-induced glutamate release in cerebellar slices. Neuropharmacology 43(3) 374-384. https://doi.org/10.1016/s0028-3908(02)00094-1

32. Uteshev $\mathrm{V}$ (2014) The therapeutic promise of positive allosteric modulation of nicotinic receptors. European journal of pharmacology 727 181-185. https://doi.org/10.1016/j.ejphar.2014.01.072

33. Dineley KT, Pandya AA, Yakel JL (2015) Nicotinic ACh receptors as therapeutic targets in CNS disorders. Trends in pharmacological sciences 36(2) 96-108 (2015). https://doi.org/10.1016/j.tips.2014.12.002 
34. Yang T, Xiao T, Sun Q, Wang K (2017) The current agonists and positive allosteric modulators of $\alpha 7 \mathrm{nAChR}$ for CNS indications in clinical trials. Acta pharmaceutica Sinica. B 7(6) 611-622. https://doi.org/10.1016/i.apsb.2017.09.001

35. Bouzat C, Lasala M, Nielsen BE, Corradi J, Esandi M (2018) Molecular function of $\alpha 7$ nicotinic receptors as drug targets. The Journal of physiology 596(10) 1847-1861. https://doi.org/10.1113/JP275101

36. Fucile S (2004) Ca2+ permeability of nicotinic acetylcholine receptors. Cell calcium 35(1) 18. https://doi.org/10.1016/i.ceca.2003.08.006

37. Guan YZ, Jin XD, Guan LX et al (2015) Nicotine inhibits microglial proliferation and is neuroprotective in global ischemia rats. Molecular neurobiology 51(3) 1480-1488. https://doi.org/10.1007/s12035-014-8825-3

38. Kabbani N, Nordman JC, Corgiat BA et al (2013) Are nicotinic acetylcholine receptors coupled to $G$ proteins? BioEssays: news and reviews in molecular, cellular and developmental biology 35(12), 1025-1034. https://doi.org/10.1002/bies.201300082

39. Changeux JP, Taly A (2008) Nicotinic receptors, allosteric proteins and medicine. Trends in molecular medicine 14(3) 93-102. https://doi.org/10.1016/j.molmed.2008.01.001

40. Chatzidaki A, Millar NS (2015) Allosteric modulation of nicotinic acetylcholine receptors. Biochemical pharmacology 97(4) 408-417. https://doi.org/10.1016/j.bcp.2015.07.028

41. Bertrand D, Gopalakrishnan M (2007) Allosteric modulation of nicotinic acetylcholine receptors. Biochemical pharmacology 74(8) 1155-1163. https://doi.org/10.1016/i.bcp.2007.07.011

42. Grønlien JH, Håkerud M, Ween $\mathrm{H}$ et al (2007) Distinct profiles of alpha7 nAChR positive allosteric modulation revealed by structurally diverse chemotypes. Molecular pharmacology 72(3) 715-724. https://doi.org/10.1124/mol.107.035410

43. Noviello CM, Gharpure A, Mukhtasimova $\mathrm{N}$ et al (2021) Structure and gating mechanism of the $\alpha 7$ nicotinic acetylcholine receptor. Cell 184(8) 2121-2134.e13. https://doi.org/10.1016/j.cell.2021.02.049

44. Mukhtasimova N, Lee WY, Wang HL, Sine SM (2009) Detection and trapping of intermediate states priming nicotinic receptor channel opening. Nature 459 (7245) 451-454. https://doi.org/10.1038/nature07923

45. Hansen SB, Sulzenbacher G, Huxford T et al (2005) Structures of Aplysia AChBP complexes with nicotinic agonists and antagonists reveal distinctive binding interfaces and conformations. The EMBO journal 24(20) 3635-3646. https://doi.org/10.1038/sj.emboj.7600828

46. Hibbs RE, Sulzenbacher G, Shi J et al (2009) Structural determinants for interaction of partial agonists with acetylcholine binding protein and neuronal alpha7 nicotinic acetylcholine receptor. The EMBO journal 28(19) 3040-3051. https://doi.org/10.1038/emboj.2009.227

47. Brams M, Gay EA, Sáez JC et al (2011) Crystal structures of a cysteine-modified mutant in loop D of acetylcholine-binding protein. The Journal of biological chemistry $286(6) 4420$ 4428. https://doi.org/10.1074/jbc.M110.188730

48. Fabiani C, Murray AP, Corradi J, Antollini SS (2018) A novel pharmacological activity of caffeine in the cholinergic system. Neuropharmacology 135 464-473. https://doi.org/10.1016/i.neuropharm.2018.03.041

49. Pereira EF, Hilmas C, Santos MD et al (2002) Unconventional ligands and modulators of nicotinic receptors. Journal of neurobiology 53(4) 479-500. https://doi.org/10.1002/neu.10146

50. Spurny R, Debaveye S, Farinha A et al (2015) Molecular blueprint of allosteric binding sites in a homologue of the agonist-binding domain of the $\alpha 7$ nicotinic acetylcholine receptor. Proceedings of the National Academy of Sciences of the United States of America 112(19) E2543-E2552. https://doi.org/10.1073/pnas.1418289112

51. Young GT, Zwart R, Walker AS, Sher E, Millar NS (2008) Potentiation of alpha7 nicotinic acetylcholine receptors via an allosteric transmembrane site. Proceedings of the National Academy of Sciences of the United States of America 105(38) 14686-14691. https://doi.org/10.1073/pnas.0804372105 
52. Neher E, Steinbach JH (1978) Local anaesthetics transiently block currents through single acetylcholine-receptor channels. The Journal of physiology 277 153-176. https://doi.org/10.1113/iphysiol.1978.sp012267

53. Parrish WR, Rosas-Ballina M, Gallowitsch-Puerta M et al (2008) Modulation of TNF release by choline requires alpha7 subunit nicotinic acetylcholine receptor-mediated signaling. Molecular medicine (Cambridge, Mass.) 14(9-10) 567-574.

https://doi.org/10.2119/2008-00079.Parrish 
Figures

A

B

SARS-CoV-2 Spike

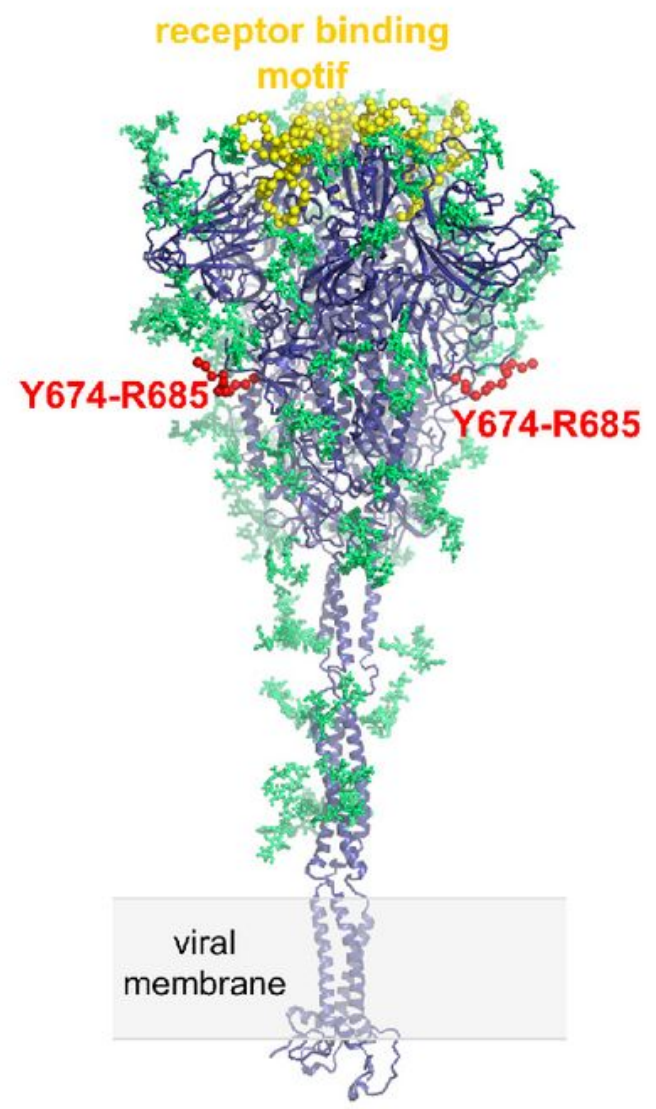

C

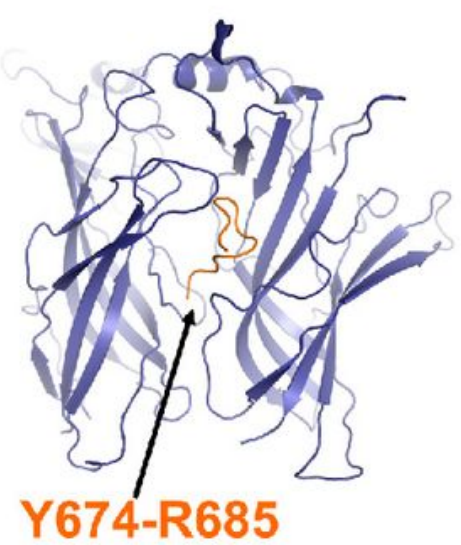

$\alpha 7 \mathrm{nAChR}$
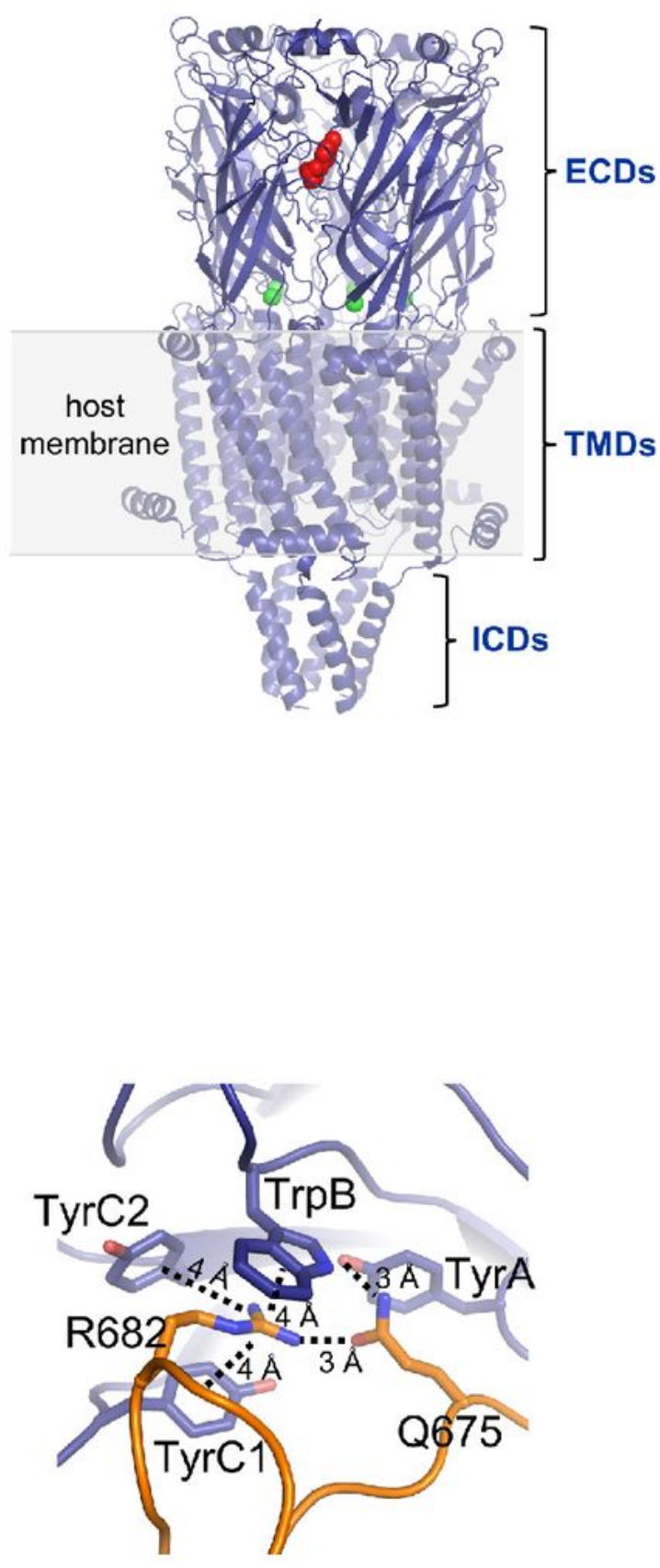

Figure 1

Three-dimensional structures of the SARS-CoV-2 S protein and the human a7 nAChR. 
A. The model represents the complete, fully glycosylated S protein in the closed state after furin cleavage [1]. The protein is rendered as a blue cartoon with the glycans depicted in green. The receptor binding motifs (residues S438-Q506) and the Y674-R685 region are highlighted in yellow and red, respectively. The Y674-R685 region was shown to be accessible for binding in previous MD simulations of the fully glycosylated S protein [8].

B. Cryo-EM structure of the human a 7 AChR (PDB code: 7KOX) [43]. This receptor is a homopentamer formed of five a7 subunits. Each subunit is composed of an extracellular (ECD), transmembrane (TMD) and intracellular (ICD) domain. The agonist binding site is located in the ECD at the interface between two neighbouring subunits. In this structure, epibatidine (red spheres) is bound to the agonist binding site. The green spheres represent bound calcium ions.

C. MD simulations of Y674-R685 bound to the human a7 nAChR show favourable binding to the binding pocket [8]. Example of conformations from simulations in which the most important interactions with conserved key aromatic residues are present. Left: Overall view of the Y674-R685: a7(ECD) complex. Right: Close-up view of interactions formed by R682 and Q675 within agonist binding site. The a7 receptor and Y674-R685 are coloured in dark blue and orange, respectively. Interactions between side chains of R682 and Q675 and the aromatic rings of TrpB (a7W171), TyrC1 (a7Y210), TyrC2 (a7Y217) and TyrA (a7Y115) are shown with dashed lines.

A
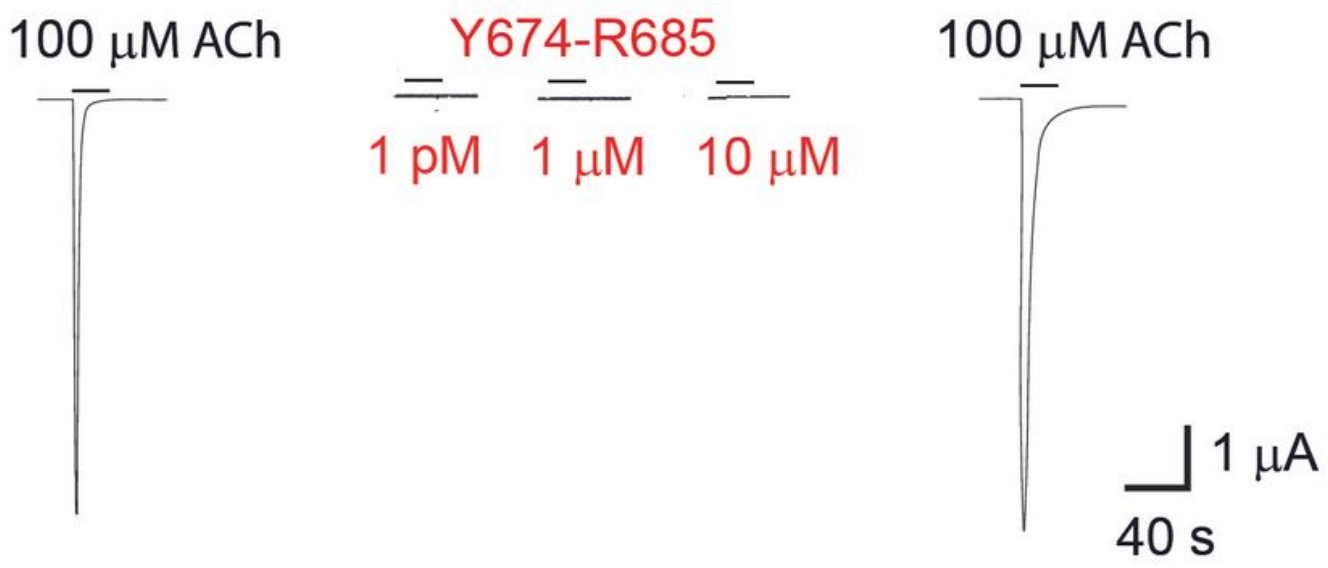

B

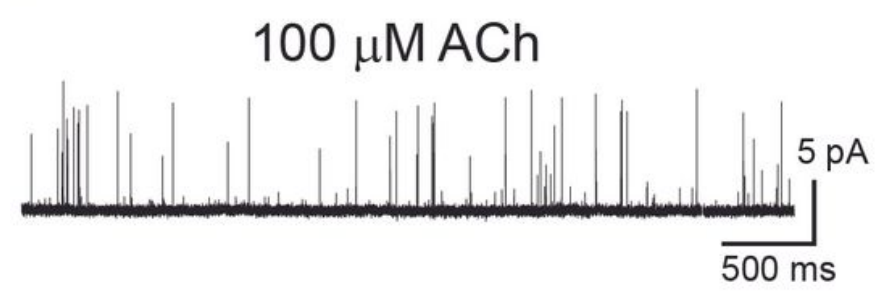

$10 \mu \mathrm{M}$ Y674-R685

Figure 2

The Y674-R685 fragment cannot elicit detectable a7 responses. 
A. Macroscopic responses of the human a $7 \mathrm{nAChR}$. Representative traces from single oocytes expressing human a 7 nAChR to applications of ACh (100 $\mu \mathrm{M})$ or $1 \mathrm{pM}, 1 \mathrm{mM}$ or $10 \mathrm{mM}$ of Y674-R685. Drug applications were for $20 \mathrm{~s}$ followed by a $300 \mathrm{~s}$ washout.

B. Single-channel currents of the human a 7 AChR recorded from cell-attached patches in the presence of $100 \mu \mathrm{M}$ ACh or $10 \mu \mathrm{M}$ Y674-R685. No channel activity was detected at a 1 pM-100 $\mu \mathrm{M}$ Y674-R685 concentration range. Channel openings are shown as upward deflections. Membrane potential: -70 mV. Filter: $9 \mathrm{kHz}$.

A

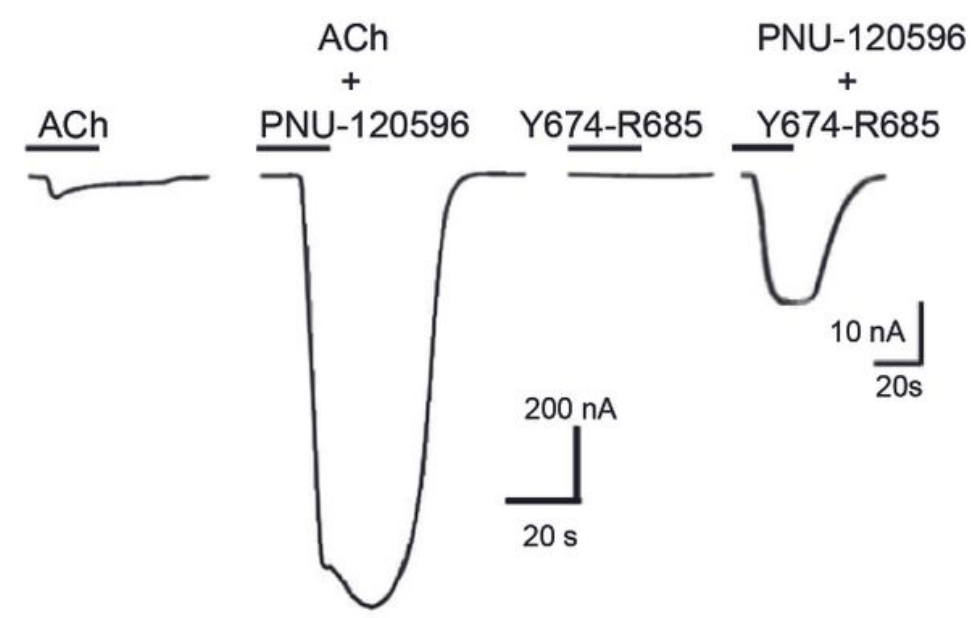

B

$10 \mu \mathrm{M} \mathrm{ACh}+1 \mu \mathrm{M}$ PNU-120596

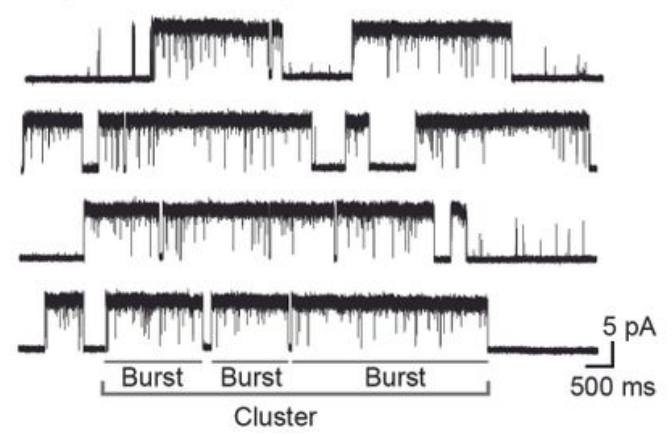

1 pM Y674-R685 + 1 $\mu$ M PNU-120596

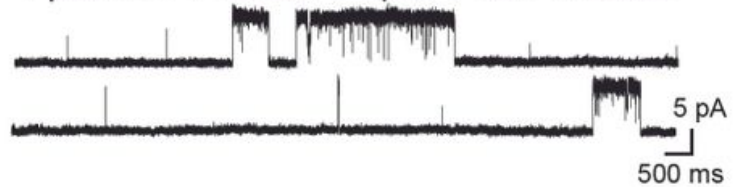

$10 \mu \mathrm{M}$ Y674-R685 + 1 $\mu \mathrm{M}$ PNU-120596

Figure 3

Activation of the human a7 nAChR by Y674-R685 in the presence of the PAM PNU-120596.

A. Macroscopic currents were recorded from oocytes expressing the human a7 nAChR after a pulse of 30 $\mu M$ ACh (control) or $1 \mu M$ Y674-R685 in the absence or presence of $10 \mu M$ PNU-120596. Current traces shown are representative of $n=15$ recordings from oocytes isolated from $N=3$ donors.

B. Single-channel currents of the human a7 nAChR in the presence of the type II PAM PNU-120596 (1 $\mu M)$ activated by $100 \mu \mathrm{M}$ ACh (left), or Y674-R685 at 1 pM or $10 \mu \mathrm{M}$ (right). For each condition typical channel traces are shown. Channel openings are shown as upward deflections. Membrane potential: $-70 \mathrm{mV}$. Filter: $3 \mathrm{kHz}$. 


\section{Figure 4}

\section{Single-channel recordings of the human a7 nAChR in the presence of Y674-R685.}

Single-channel currents of human a7 nAChR in the presence of the type II PAM PNU-120596 (1 $\mu M)$ activated by $100 \mu \mathrm{M}$ ACh, or Y674-R685 at $1 \mathrm{pM}$ or $10 \mu \mathrm{M}$. For each condition, channel traces at two different temporal scales are shown. Channel openings are shown as upward deflections. Representative open, burst and cluster duration histograms are shown for each condition. The open, burst and cluster durations correspond to the durations of the slowest components of each histogram. The dashed lines show how these mean durations change among different conditions. Membrane potential: -70 mV. Filter: $3 \mathrm{kHz}$.

\section{Figure 5}

\section{Channel activity elicited by Y674-R685 in the absence or presence of the PAM.}

Representative experiments in which channel activity from the same patch was recorded before and after addition of PNU-120596. ACh or $10 \mu M$ Y674-R685 were present in the pipette solution.

The indicated time corresponds to the time of recording after addition of PNU-120596.

Top: Single-channel currents of human a7 activated by $100 \mu \mathrm{M}$ ACh appeared mainly as brief isolated openings. Addition of $1 \mu \mathrm{M}$ PNU-120596 to the extracellular solution surrounding a cell-attached patch resulted in a marked increase in current in the continued presence of $100 \mu \mathrm{M} \mathrm{ACh}$ in the patch pipette. This experiment is representative of 4 different patches.

Bottom: Channel activity was undetectable in the presence of Y674-R685. Addition of $1 \mu M$ PNU-120596 to the extracellular solution surrounding the silent patch revealed channel activity, indicating that only in the presence of the PAM $10 \mu M$ Y674-R685 can activate a7. This experiment is representative of 3 different patches.

Channel openings are shown as upward deflections. Membrane potential: -70 mV. Filter $3 \mathrm{kHz}$. 


\section{Figure 6}

\section{Activation of the human a7 nAChR by Y674-R685 in the presence of the type I PAM, 5-HI.}

Single-channel currents were recorded from cells expressing the human a7 nAChR in the presence of 2 mM 5-HI as the PAM and $100 \mu M$ ACh or $10 \mu M$ Y674-R685 as agonists. Traces at two different scales are shown for each condition. Membrane potential: -70 mV, Filter: 9 kHz. Representative open and burst duration histograms are shown for each agonist. The bar chart shows the mean durations of open and bursts for each agonist ( $n=37$ for $A C h$, and $n=3$ for Y674-R685). ${ }^{*} p<0.05, * * p<0.01$.

\section{Figure 7}

\section{Y674-R685 Inhibition of a7 nAChR channels activated by ACh.}

A. Single-channel currents elicited by $10 \mu M$ ACh and potentiated by $1 \mu M$ PNU-120596 were recorded in the absence (control) or presence of 1 or $10 \mu M$ Y674-R685.

Left: Typical channel traces are shown at two different temporal scales. Channel openings are shown as upward deflections. Membrane potential: -70 mV. Filter: $3 \mathrm{kHz}$.

Right: Bar chart showing the mean durations of openings (topen), bursts (tburst) and clusters (tcluster) in the absence and in the presence of $1 \mathrm{pM}, 1 \mathrm{nM}, 1 \mu \mathrm{M}$ and $10 \mu \mathrm{M}$ Y674-R685.

${ }^{* *} p<0.01,{ }^{* *} p<0.001$ (Student-t Test) (Supplementary Table 1).

B. Left Panel: Concentration response curve (CRC) for the inhibition of the a7 nAChR by Y674-R685. Increasing concentrations of Y674-R685 (0.1 nM to $30 \mu \mathrm{M})$ were co-applied with control ACh (100 $\mu \mathrm{M})$. Responses were measured fom the peak of ACh-elicited currents. Each data point represents the average normalized response of six cells ( \pm SEM).

Right Panel: Competition CRC data (red) for $1 \mu$ M Y674-R685 co-applied with different ACh concentrations (0.1-2000 $\mu \mathrm{M})$. For comparison, ACh CRC data alone (black) are shown at the same concentrations. Data were fitted with the Hill equation, as described in Methods. Data points represent the average normalized response of six oocytes ( \pm SEM).

\section{Supplementary Files}

This is a list of supplementary files associated with this preprint. Click to download.

- SupportingInformationChrestiaetal2022.pdf 